\title{
Energy Poverty and Low Carbon Just Energy Transition: Comparative Study in Lithuania and Greece
}

\author{
Dalia Streimikiene $^{1} \mathbb{D} \cdot$ Grigorios L. Kyriakopoulos $^{2}$ (D) . Vidas Lekavicius ${ }^{1}$. \\ Indre Siksnelyte-Butkiene ${ }^{3}$ (i)
}

Accepted: 13 April 2021 / Published online: 29 April 2021

(C) The Author(s), under exclusive licence to Springer Nature B.V. 2021

\begin{abstract}
EU has set ambitious commitment to achieve low carbon energy and economy transition up to 2050. This low carbon transition means sustainable energy development path based on renewable energy sources and first of all should address the energy poverty vulnerability and justice issues. The main goal of the paper is to develop indicators framework for assessing low carbon just energy transition and to apply this framework for analysis how climate change mitigation policies in households targeting enhancement of energy renovation of residential buildings and promotion of the use of micro-generation technologies and other policies are affecting household's energy poverty and vulnerability in selected countries: Lithuania and Greece. This framework allows to assess three main dimensions of sustainable energy development: environmental, social and economic. The paper provides policy recommendations how to deal with just low carbon energy transition which means addressing energy poverty issues during moving to $100 \%$ renewables in power generation based on performed case studies.
\end{abstract}

Keywords Energy poverty · Just low carbon energy transition · Indicators framework · Policy assessment $\cdot$ Greece $\cdot$ Lithuania

Dalia Streimikiene

dalia@mail.lei; dalia.streimikiene@lei.lt

Grigorios L. Kyriakopoulos

gregkyr@chemeng.ntua.gr

Vidas Lekavicius

vidas.lekavicius@lei.lt

Indre Siksnelyte-Butkiene

indre.siksnelyte@knf.vu.lt

1 Lithuanian Energy Institute, Beslaujos 3, 44403 Kaunas, Lithuania

2 Photometry Laboratory, Electric Power Division, School of Electrical and Computer Engineering, National Technical University of Athens, 15780 Athens, Greece

3 Kaunas Faculty, Vilnius University, Muitines 8, LT-44280 Kaunas, Lithuania 


\section{Introduction}

The problem of energy vulnerability, energy poverty and energy justice are being currently widely discussed among the relevant published studies. Due to the targets set by EU policy documents to achieve climate neutral society by 2050 , it is especially important to address low carbon transition justice and energy poverty issues. There is debate among scientists with regards to energy poverty and low carbon energy transition signifying that climate change mitigation policies implemented in energy and related sector will not serve for economic and social development and energy poverty alleviation (Bowen et al., 2014; Colenbrander et al., 2016; Larson et al., 2015; Schwanen et al., 2011). Consequently, it was claimed that climate actions are not systematic and the costs of required actions are too high in relation to capacities to bear these costs (Bos \& Gupta, 2019; Jewell \& Cherp, 2020). Therefore, Lazarou et al. (2018), Kang et al. (2020) and Zhang and Fujimori (2020) suggest additional actions as necessary to ensure technological innovation which is due to optimal technology portfolio selection along with financial and political incentives. In addition, early investments in climate change mitigation in middle-income countries need to be ensured (Colenbrander et al., 2016) as these will experience many problems (Bos $\&$ Gupta, 2019). It was also stressed out that innovation and economic diversification are considered key complementary measures to be implemented in preparation of successful climate mitigation strategies and penetration of renewable energy sources (RES) in energy markets (Edenhofer et al., 2011; Fuss et al., 2012; Massetti \& Tavoni, 2011). Renewables are valued as the main measure to alleviate energy poverty in remote areas not having access to modern energy services (Boemi et al., 2020; Chakravarty \& Tavoni, 2013; Zerriffi and Wilson, 2010). However, according to other studies related to the achievement of just low carbon transition, the supportive and well targeted policies, standards and realistic and flexible initiatives are necessary (Arabatzis \& Myronidis, 2011; Grigoropoulos et al., 2020; Kolovos et al., 2011; Ntanos et al., 2016; Yuksel, 2008). It is also noteworthy that in low carbon transition debates it has been stressed out the importance of redesigning of urban landscapes and protected areas, as well as the selection of energy performance indicators and environmental criteria to achieve minimization of energy consumption at no cost, especially at the built environment (Ardavani et al., 2020; Doulos et al., 2019, 2020; Mavridou \& Doulos, 2019; Papalambrou et al., 2019).

Similarly there are studies arguing that energy poverty alleviation in developing nations and provision of universal access to modern energy could significantly increase energy demand and associated $\mathrm{CO}_{2}$ emissions (Chakravarty \& Tavoni, 2013; Nathan \& Hari, 2020). However, it is also literature-proven that win-win policies in terms of social, health and environmental objectives may be achieved in the short-term, improving the public policies related to environmental sustainability, GHG mitigation, access to clean energy (De Martino Jannuzzi, 2010; Drosos et al., 2020; Huang et al., 2020; Serrano-Medrano et al., 2018; Zamparas, Kyriakopoulos, et al., 2019). It has been also literature argued that additional policies to improve access, availability and affordability of electricity and increased awareness on energy conservation are necessary in developing nations to ensure reduction in energy poverty and greenhouse gas(GHG) emission (Yadav et al., 2019; Boemi et al., 2020; Sharma et al., 2019; Charlier \& Kahouli, 2019; Romero Rodríguez et al., 2018). Most of those studies analysing energy poverty issues and interaction of these with climate change mitigation policies, they stressed importance of behavioral changes, education, awareness rising and training to achieve success in both policy fields (Awaworyi Churchill \& Smyth, 2020; Gouveia et al., 2018; Huang et al., 2020; Middlemiss \& Gillard, 2015; 
Nathan \& Hari, 2020; Scarpellini et al., 2015; Sharma et al., 2019). Therefore, there is no agreement among literature studies in terms of effect of GHG emission reduction policies on energy poverty alleviation. The principal scientific debate is linked to various circumstances, techniques and indicators in assessment of energy poverty, energy vulnerability and just low carbon transition (Awaworyi Churchill \& Smyth, 2020; Charlier \& Kahouli, 2019; Gillard et al., 2017; Gouveia et al., 2018; Llera-Sastresa et al., 2017; Longe \& Ouahada, 2018; Middlemiss \& Gillard, 2015; Nathan \& Hari, 2020; Sadath \& Acharya, 2017; Scarpellini et al., 2015) however the comprehensive framework to address these interlinked issues is not available. Based on the literature review the main themes that have been investigated in the climate change mitigation can be grouped and presented as follows:

- Social, in terms of synergies developed.

- Environmental, in terms of GHGs emitted.

- Agricultural, in terms of plantation and forestry management.

- Regulatory, focusing on the mitigation strategy of carbon capture and storage (CCS) and the abiding cost-effective analyses.

\subsection{Social Domain}

Regarding the social domain, besides driving mitigation of GHGs, it was proven that climate change mitigation actions can deliver non-climate benefits (co-impacts assessment) but can also cause adverse side-effects (Cohen et al., 2021). Co-impacts assessment aiming at identifying those co-benefits and adverse side-effects, fostering our knowledge of undertaken mitigation actions, planning interventions that realize synergistic opportunities and contribute simultaneously to multiple objectives, and increasing the efficiency and costeffectiveness of climate actions (Cohen et al., 2021). Consequently, at this study it was proposed that in the context of Sustainable Development Goals (SDGs), such a co-benefits approach can cohesively incentivize stakeholders to work together to support climate change mitigation policies and non-climate objectives. Besides, the better understanding of adverse side-effects can ensure the recognition and control of those trade-offs with delivery of the SDGs arising from mitigation actions (Cohen et al., 2021).

In a similar, social-driven, study it was stressed out that the mobilization of private finance in Sub-Saharan African (SSA) countries can play a decisive role to jointly achieve both Sustainable Development Goal (SDG) 7 that call for universal energy access and climate change mitigation goals that have been defined under the Paris Agreement (Michaelowa et al., 2021). It is also noteworthy that among developing or emerging economies, e.g. Ethiopia, Madagascar and South Africa, the illustration of ways under which climate finance interacts with domestic policy instruments, cannot follow a "catch all" success model. Therefore, approaches need to be tailored to local circumstances, while key policy insights from international market mechanisms and climate finance they are attracting private multibillion-dollar investment in energy access and climate mitigation, even under the challenging conditions facing many SSA nations (Michaelowa et al., 2021). Moreover, the association developed between international and regional development programs at these developing countries with the international carbon market might be feasibly close the financing gaps and establish synergies between climate goals and SDGs ((Michaelowa et al., 2021). In this respect, while it is a necessity of more empirical researches to be conducted for a better understanding the magnitude of synergistic benefits between different measures, those measures related to green infrastructure, buildings, 
energy systems, and, transportation are particularly capable to provide co-benefits and to support synergies. Besides, such a measures can be focused on urban indicators like appropriate levels of density, promotion of public transportation, and urban greenery, which are all more likely to provide synergistic benefits if combined with other adaptation or mitigation measures (Sharifi, 2021). In this respect, while it is a necessity of more empirical researches to be conducted for a better understanding the magnitude of synergistic benefits between different measures, those measures related to green infrastructure, buildings, energy systems, and, transportation are particularly capable to provide co-benefits and to support synergies. Besides, such a measures can be focused on urban indicators like appropriate levels of density, promotion of public transportation, and urban greenery, which are all more likely to provide synergistic benefits if combined with other adaptation or mitigation measures (Sharifi, 2021).

\subsection{Environmental Domain}

Regarding the linkages developed between the anticipated GHGs reduction and the implementation of climate change mitigation strategies, a systematic analysis of barriers hindering the emission reduction, e.g. climate risks, pollutants, and other adverse environmental impacts were considered at the industrial sector (Balsara et al., 2021). However, the majority of existing research has focused on the barriers to mitigation measures among developed countries. Contrarily, there are also other countries of research interest; among them, India is one of the most important emerging economies, as the second-largest producer and consumer of cement, facing challenges to implement emission reduction measures (Balsara et al., 2021). At this study they were employed the methodologies of fuzzy analytical hierarchy process (AHP) and fuzzy technique for order performance, in alignment with their similarity to ideal solution (TOPSIS). Then, the barriers and solution strategies to overcome these barriers were specifically proposed in the Indian cement industry. It can be signified that the adoption and running of effective decision support tools to specific industrial -thus energy intensive and heavily polluting- sectors could, first, eliminate and overcome barriers to mitigation strategies adoption and, second, build their green image in the market (Balsara et al., 2021).

\subsection{Agricultural and Forestry Domain}

Regarding the agricultural and forestry domain it is noteworthy that agriculture is a climate dependent activity, being reciprocally affected by climate change and contribute to climate change. In particular the agricultural sector necessitates the production of more food for a starving world, demanding large inputs of nitrogen-based fertilizers while high GHG-generated nitrous oxide (NOx) emissions (Saavedra et al., 2021). Another GHG is that of carbon dioxide that is beneficial for some vegetable species. Climate change is also affected by elevated temperatures in vegetable production and distorting the physiology of plants, the pollination cycle and the fruit set. Consequently, due to seasonal imbalances of cold and warm periods, new zones will be incorporated to vegetable production, though it is impossible to produce larger amounts of quality vegetable for temperature. Mitigation of climate change is a complex task that involves many actors including government policies and, even more important, peoples' conscience and awareness. Breeders should exert intense efforts to generate varieties tolerant to many stresses, e.g. high temperature and low 
production, being able to respond to biotic and abiotic stresses caused by climate change (Saavedra et al., 2021).

In a regional level of agricultural-driven analyses there were studied the climate change mitigation policies in five major emitting economies: China, the European Union, India, Japan and the United States (Fekete et al., 2021). In this study they were examined the indicators of energy system and GHG emissions indicators, focusing on policies that can reduce future emissions. Among aspects of such environmental and energy impact, that of agriculture and forestry were examined into policies-scenarios' deployment. In this context it was reported that all examined countries would overachieve the emissions reduction targets in their post-2020 climate targets (Fekete et al., 2021). However, the anticipated GHG reduction in global emissions by 2030 would not promisingly keep the world on track for a global cost-effective pathway in terms of temperature increase below $2{ }^{\circ} \mathrm{C}$, thus, necessitating transformative policies to keep the Paris Agreement temperature limit as targeted (Fekete et al., 2021).

Another critical issue of the agri-food sector is that of carbon neutral labeling of food products, being a market-based approach to reduce carbon footprints. To better understand consumers' preferences and attitudes towards a carbon neutral label on globally traded agri-food products, the willingness to pay (WTP) of German consumers for a carbon neutral label on specialty coffee was examined (Birkenberg et al., 2021). A discrete choice experiment was conducted in Germany, where coffee is often sold with multiple labels or claims, showing a positive synergy effect on utility for the combination of a carbon neutral label and a direct trade claim. In a trading point of view consumers often perceived coffee as a "natural product" without generating any GHG emissions. Therefore, there were proposed the drawing of awareness-building policies to make carbon neutral labels an effective market-based tool to reduce GHG emissions in the agri-food sector (Birkenberg et al., 2021).

Moreover, another critical viewpoint of the aforementioned synergy is that developed among crop production, water pollution and climate change mitigation. In particular the developed synergies are determined between (a) climate change mitigation and water protection goals and, (b) a trade-off between pollution mitigation and crop production goals (Sihvonen et al., 2021). Whenever a field is a significant source of GHG emissions and an insignificant source of water pollution, atmospheric externalities are dominating over the water externalities, even for a relatively low social cost of carbon (SCC). Besides, whenever a field is a significant source of water pollution the SCC, in turn, would have to be very high before atmospheric externalities dominate water externalities (Sihvonen et al., 2021). In particular, it was also argued that GHG emissions and nitrogen and carbon leaching mitigation efforts can be primarily targeted at coarse soils rather than clay soils, because the marginal abatement costs are considerably lower for coarse soils (Sihvonen et al., 2021).

\subsection{Regulatory Domain}

Regarding the regulatory domain it is of utmost importance to state that carbon capture and storage (CCS) is considered one of the most promising mitigation strategies for carbon dioxide emissions sequestration to the atmosphere, thus, fostering the deceleration of global warming (Bonnail et al., 2021). There is an increasing demand for CCS sites, but there is a lack of knowledge of the environmental risk associated with potential leakage of carbon dioxide from the storage sites and, most important, what is happening when the 
seepage stops. It remains questionable whether the environmental carrying capacity could fully rebound, returning to the initial equilibrium (Bonnail et al., 2021).

In a geographical level, relevant analyses provided a detailed roadmap to reduce GHG emissions and to create new climate industries through early demonstration of capture and utilization (CCU) technology. Among the counties examined, the Korean government established the 2030 Greenhouse Gas Reduction Roadmap in 2016 and included carbon capture, utilization, and storage (CCUS) technology in the new energy industry sector as a CCU technology (Jung et al., 2021). It was particularly denoted that the U.S., Germany, and China also expect CCUS technology to play a decisive role in reducing GHGs in the industrial sector in terms of climate and energy policy (Jung et al., 2021). Such CCUrelated policies and technological trends in the U.S., Germany, and China included major climate and energy plans, driving roadmaps, government-led projects and institutional support systems. It was expected these regulatory tools to contribute to responding to climate change, to promote domestic GHG reduction, to create future growth engines, being also used as basic data for the establishment of CCU-related policies (Jung et al., 2021).

Taken into consideration that actions related to climate change mitigation have attained different costs and benefits, it is important to reveal whether climate change concerns and personal responsibility are equally influencing all actions related to climate change mitigation, as well as whether all types of actions are guided by the same goals (JakučionytèSkodiené \& Liobikienè, 2021). In this context the performance of actions related to climate change mitigation is varied across European countries, especially in terms of the cross-cultural analysis conducted (Jakučionytė-Skodienè \& Liobikienè, 2021). Based on this analysis, the majority of respondents declared that they followed regular separation of waste to recycling, thus, reducing waste generation. In parallel, less share of respondents performed very high-cost actions such as the purchase of low-energy homes and electric cars, implying that personal responsibility and climate change mitigation actions are driven by pure economic development motives, through primarily promoting low-cost actions, but not inspired by climate change concerns. Hofstede's cultural dimensions influence climate change concerns, responsibility, and the number of actions differently. Considering separate actions related to climate change mitigation, the assumption of personal responsibility significantly and positively influenced almost all actions. Climate change concerns positively and significantly affected only low-cost actions. Because of the different costs and guiding goals, the respondents who performed one action did not necessarily perform other actions related to climate change mitigation (Jakučionytė-Skodienė \& Liobikiené, 2021).

The paper aims to address this gap by developing indicators framework for tracking low carbon just energy transition and applying it for two case studies in selected countries: Lithuania and Greece. These two EU member states were selected because they are experiencing similar problems of energy poverty though they have completely different climate conditions. Lithuania represents middle income cold climate country in the East Europe. Greece represents southern part of Europe having problems due to the recent austerity policies. The current COVID-19 pandemic across the world will have even more severe impact on vulnerability of people and problems of just low carbon transition will become even more challenging Though there are several studies exploring energy poverty in Greece (Alexandri \& Androutsopoulos, 2020; Dagoumas \& Kitsios, 2014; Frangou et al., 2018) and Lithuania (Kyprianou et al., 2019; Streimikiene et al., 2020) these studies do not provide clear delineation of interlined issues of climate change mitigation and low carbon energy transition and energy poverty. The current paper also provides important contribution to analysis of low carbon transition implications to energy poverty and justice in Lithuania and Greece and extends the works carried by other research studies in this field. 
The rest of the paper has been structured in the following way: Sect. 2 presents systematic literature review on the topic; Sect. 3 introduces methods and data; Sect. 4 provides results of case studies; Sect. 5 discusses results and Sect. 6 concludes.

\section{Literature Review}

The literature on climate change mitigation policies and their impacts on energy efficiency improvement, use of renewable energy sources, GHG emission reduction and energy poverty have been analyzed as follows. For better understanding of key-aspects of climate change mitigation policies impacts on energy poverty, authors deployed an extensive literature search. At this literature search joint researches of relevant key-words were applied and the search outcomes were classified into the following main thematic areas: carbon transition- climate change mitigation- renewables and energy-poverty-household.

Each published paper was examined in term of field of analysis; methodology-conceptualization framework applied; identification of the main constraining points-barriers and developmental points-drivers.

Therefore, the assessment of climate change mitigation policies was structured on the aforementioned thematic areas and developmental criteria, offering a pluralistic integrated framework that consists of the Tables 1 and 2. Regarding the formulation and the retrieval history of the studies included in Table 1, the following procedure and inclusion-exclusion criteria were applied:

- The key-words of "climate change mitigation" in "title" yielded 1513 documents, a subtotal of 1492 of which were English-written documents. The other language-based results were that of French 8, German 8, Spanish 2, Chinese 1.

- From the subtotal of 1492 documents, 14 documents have been published in the year 2021, while for the subtotal of 1492 documents it was applied the exclusion criterion of publication period: 2010-2020, yielding 1272 documents, in total.

- From the subtotal of 1272, 27 documents have been published under the inclusion criteria of the words "renewables", "carbon transition" in Abstract and key-words of them. Among them, the most relevant to the scopes of our research study have been selected and included.

Regarding the formulation and the retrieval history of the studies included in Table 2, the literature procedure and the inclusion-exclusion criteria of documents' retrieval were the same as presented above. In particular, among the documents yielded for: "climate change mitigation" in "title", only English-written, period of publication 2010-2020, 1272 documents were found. From the subtotal of 1272, the sum of 52 documents has been published under the inclusion criteria of the words "energy", "poverty", "household" in Abstract and key-words of them. Among them, the most relevant to the scopes of our research study have been selected and included.

As one can notice from systematic analysis provided in Table 1 the majority of literature studies in analysis of climate change mitigation highlighted the importance of new renewable energy technologies and analysed the specific issues necessary to be addressed to implement climate change mitigation policies and achieve economic and social advancement by these policies. The importance of climate change mitigation actions in developing nations is stressed taken into account energy demand growth and energy poverty 


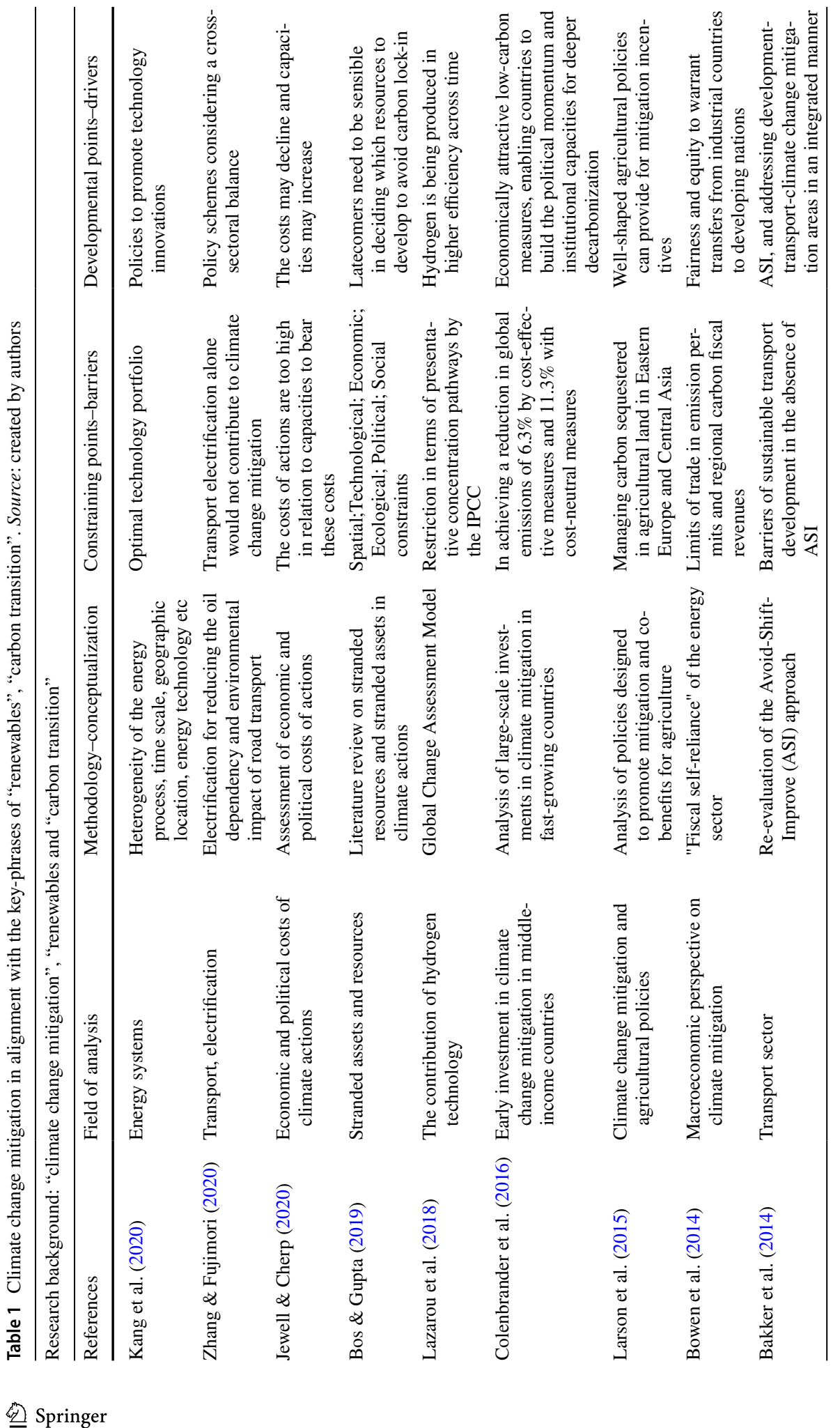




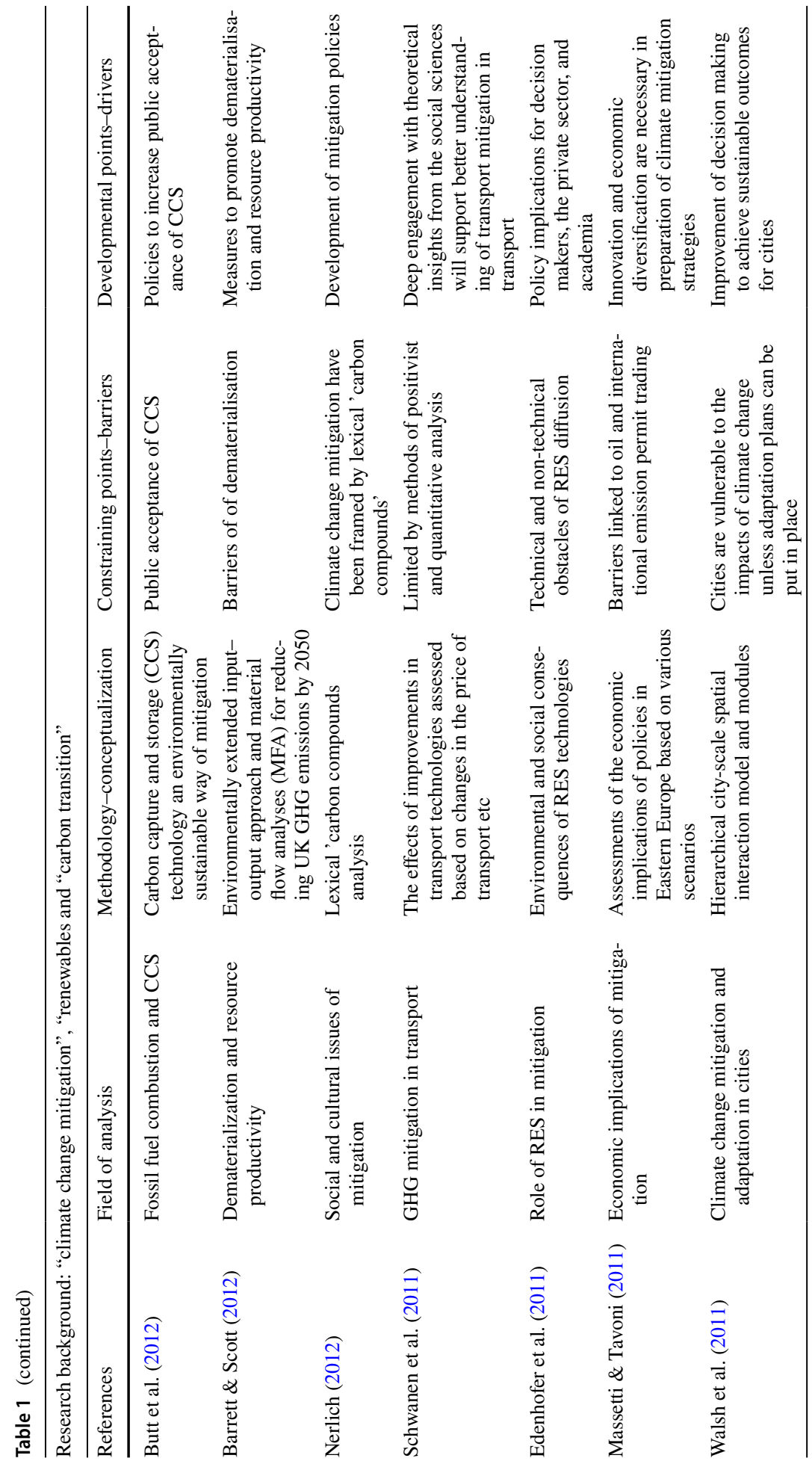




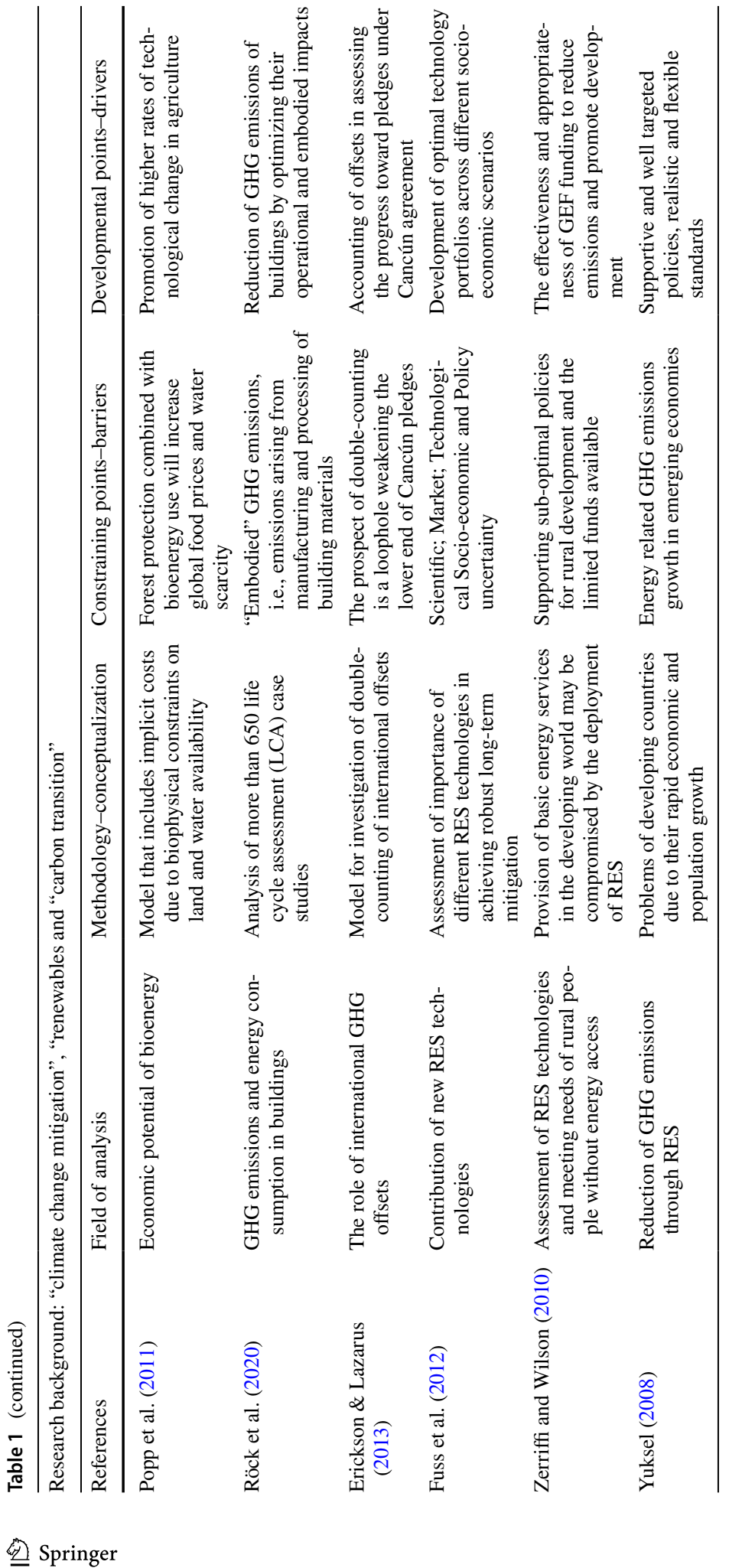




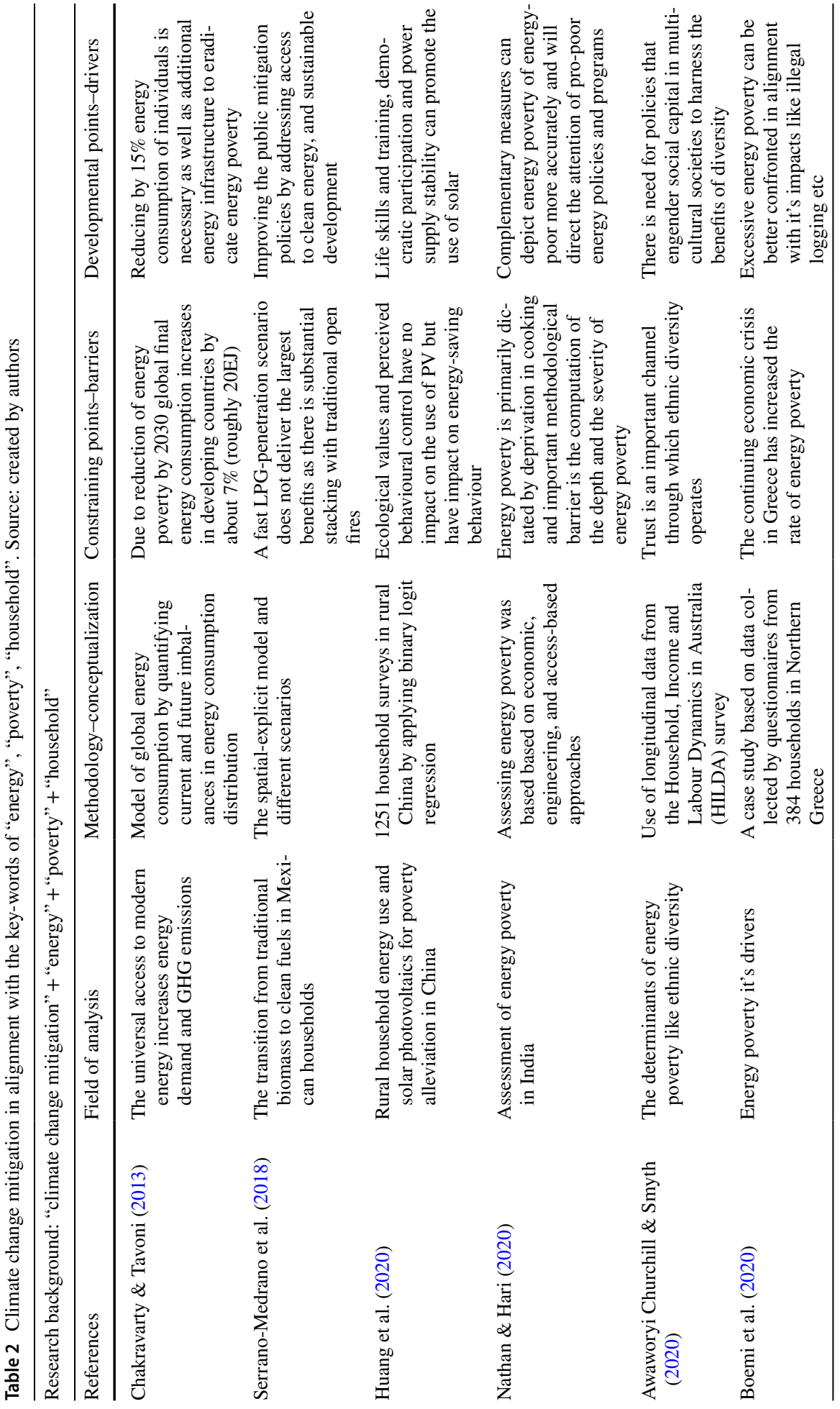




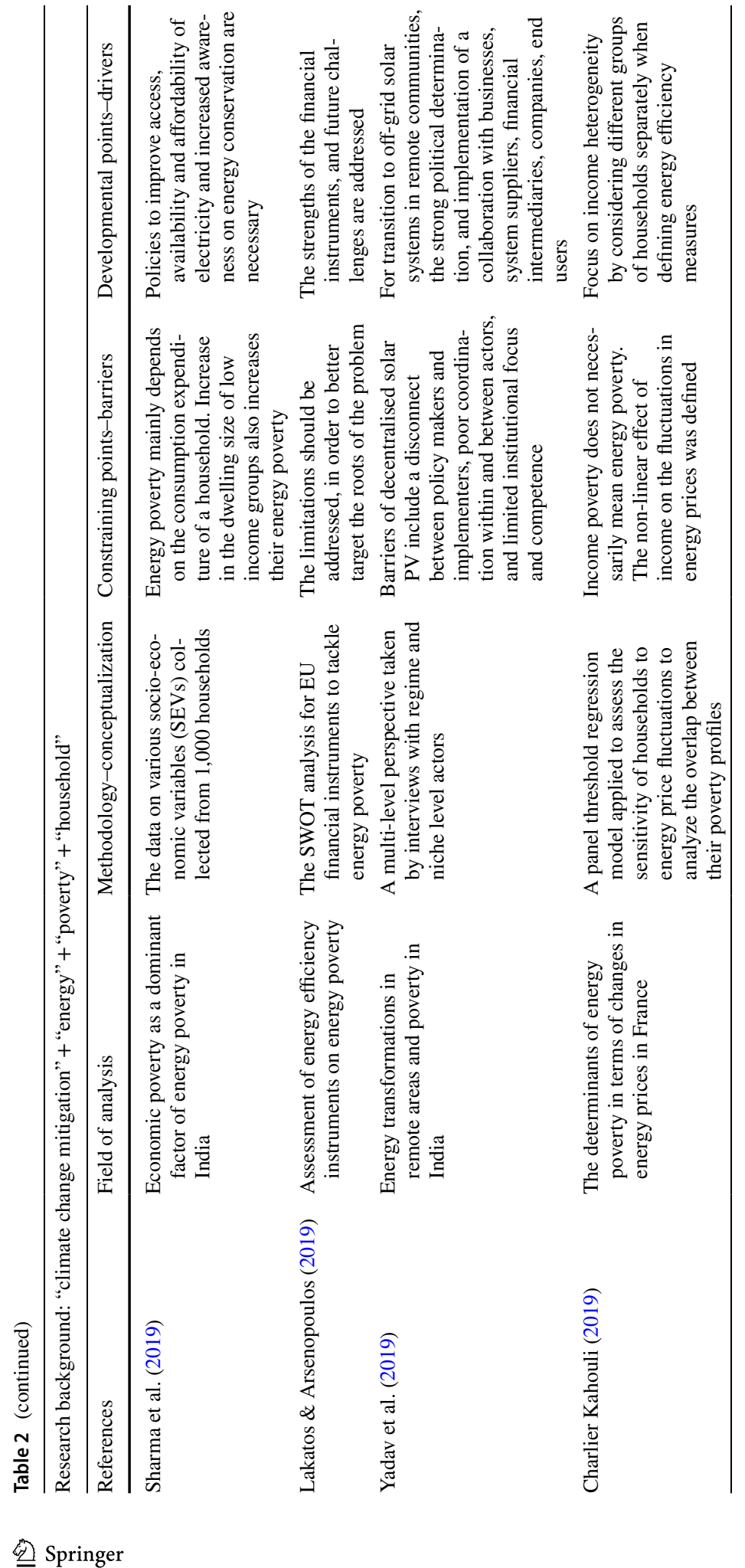




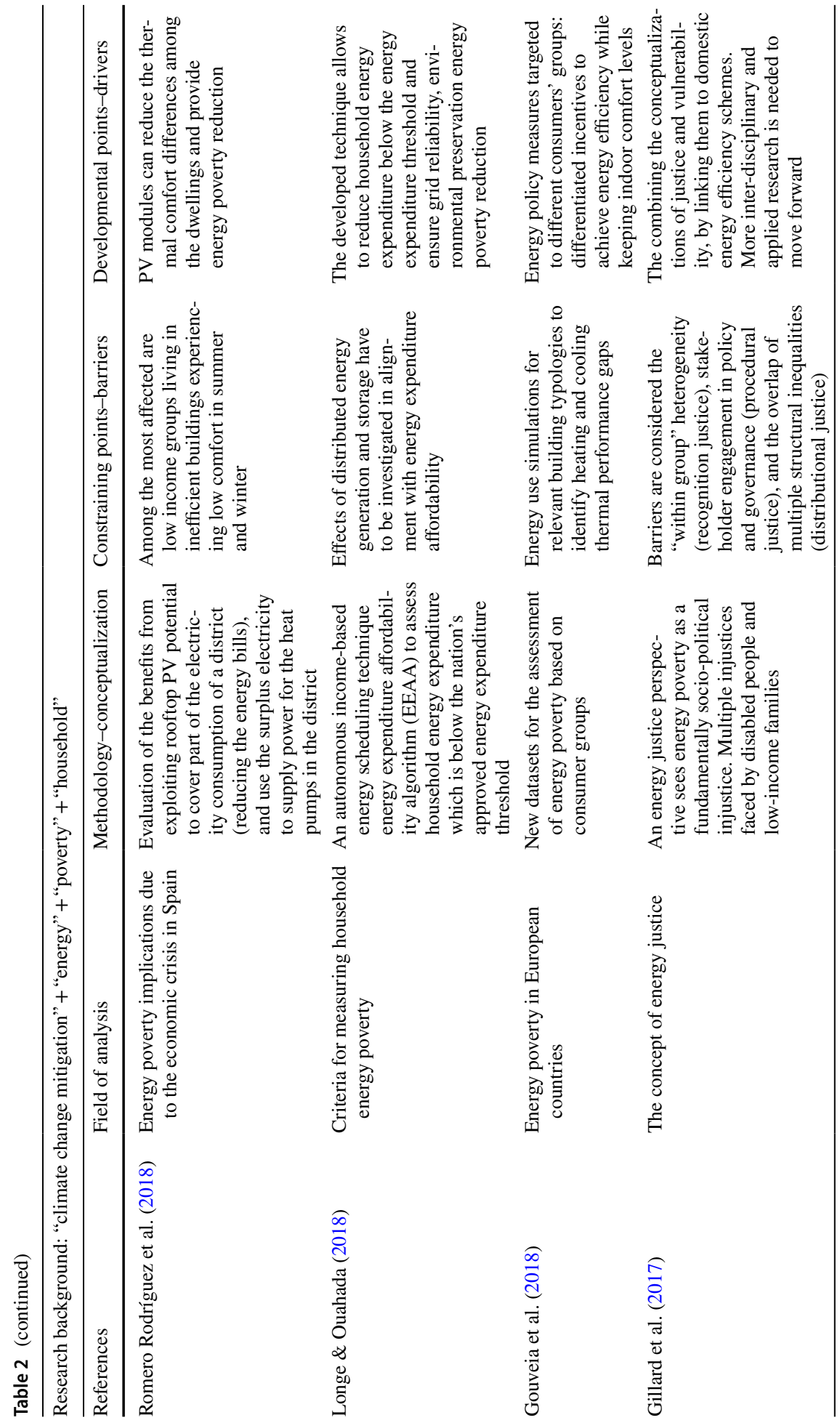




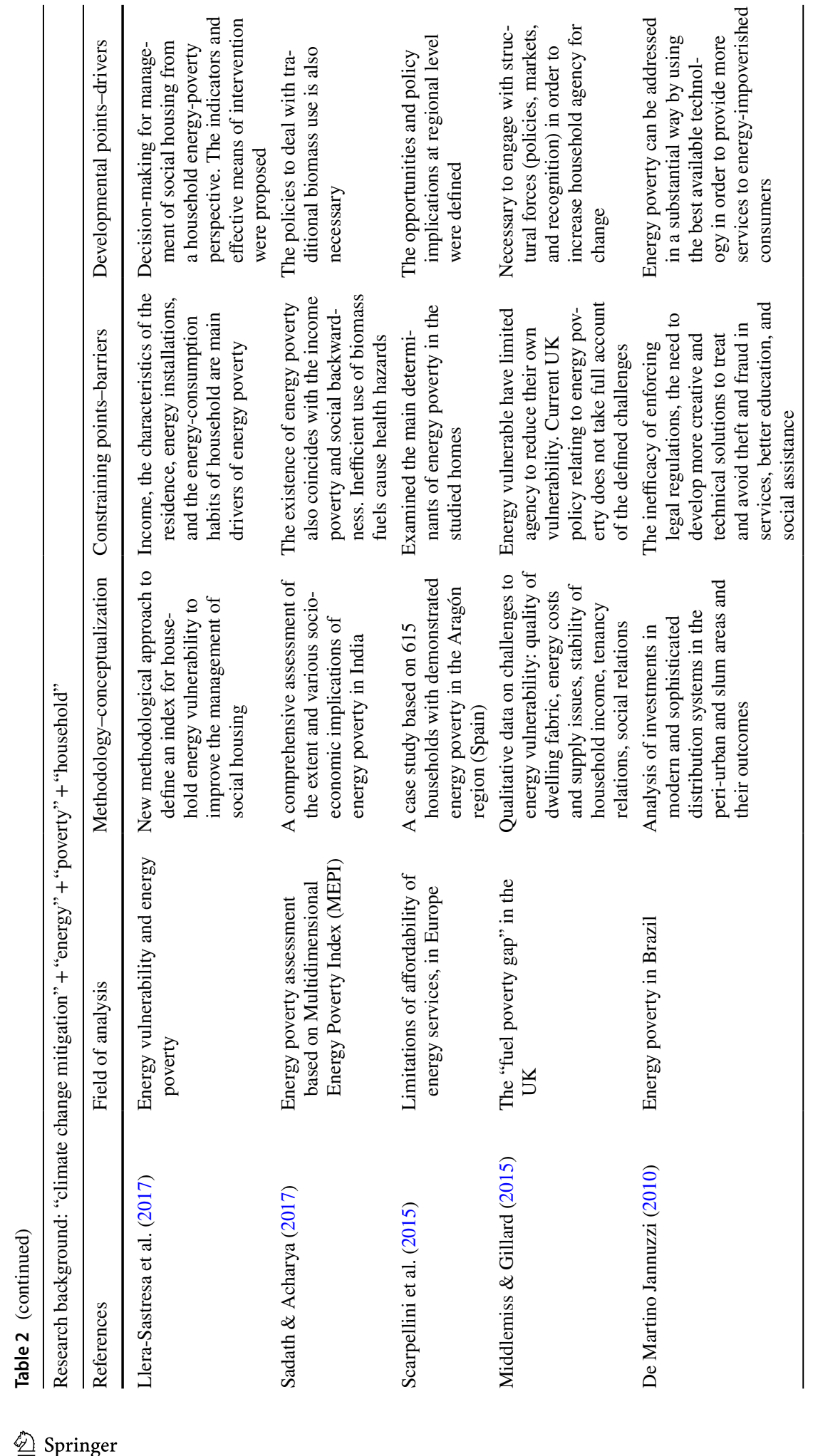




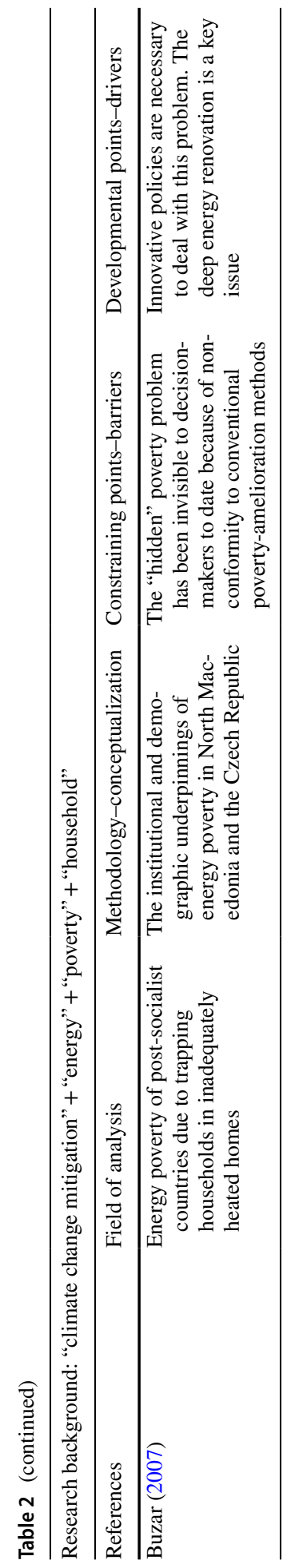


alleviation. The problem of lagging behind countries is considered and specific issues for new advanced technologies are highlighted.

The studies dealing with climate change mitigation policies alignment with energy poverty are systematized in Table 2 by applying the same approach.

As one can see from information provided in Table 2 most of the studies emphasize on addressing energy poverty issues in shaping climate change mitigation policies and making transition to low carbon energy future. The policies to promote renewable energy technologies and energy efficiency improvements can provide for energy poverty reduction in developed and developing nations (De Martino Jannuzzi, 2010; Lakatos \& Arsenopoulos, 2019; Rodríguez et al., 2018; Serrano-Medrano et al., 2018; Sharma et al., 2019). For developing economies it is the most important to develop win-win policy in terms of social, health and environmental objectives can be achieved in the short-term, improving the public policies related to GHG emission reduction and promoting long sustainable development of countries (Longe \& Ouahada, 2018; Serrano-Medrano et al., 2018).

There is no doubt that energy efficiency improvements like energy renovation of buildings have positive impacts on reduction GHG emissions, energy vulnerability and energy poverty (Buzar, 2007; Romero Rodríguez et al., 2018). In this context a similar research study unveiled the relevance of applied machine learning for climate change mitigation, focusing specifically on the fields of remote sensing, urban transportation and buildings (Milojevic-Dupont \& Creutzig, 2021). It was further denoted that the emergence of big data and machine learning methods can support climate solution research to overcome generic recommendations and provide policy solutions at urban, street, building and household scale, adapted to specific contexts, but scalable to global mitigation potentials and urban infrastructure design (Milojevic-Dupont \& Creutzig, 2021).

Chakravarty and Tavoni (2013) stress that energy poverty reduction in developing economies have negative impact on GHG emissions due to increase in energy consumption.

Gillard et al. (2017) analysed energy justice and argued that "fuel poverty" is not the issue of uneven distribution of energy but the core of socio-political injustice. The study illustrated the added value of combining the conceptualizations of justice and vulnerability, by linking them to domestic energy efficiency schemes.

Based on literature analysis it is clear that the indicators framework to track energy poverty reduction during low carbon transition is necessary to address these interrelated issues like penetration of renewables and energy efficiency improvement and energy poverty alleviation by implementing climate change mitigation policies. The inclusion of such local and regional indicators could provide an uniform methodology for the assessment of energy poverty among developing economies (Qurat-ul-Ann \& Mirza, 2020). Such a multidimensional consideration of changes in energy poverty, especially among developing economies, could be better estimated as a result of changes in energy poverty cut-off (deprivation) scores and weights (Qurat-ul-Ann \& Mirza, 2021b). The key-aspects of such multidimensional approach are the increase in latitude and proximity of household from nearby energy store, the incidence of households' receiving foreign remittances and experiencing fluctuations in annual income, the betterment of house conditions and its location in urban area, as well as the heterogeneity of primary data collected (Qurat-ul-Ann \& Mirza, 2021a). Overall, it is important to stress the linkages between climate change mitigation policies aiming at the promotion of new carbon free energy technologies and well as policies targeting energy poverty. These policies should support policymakers at all government levels to alleviate multidimensional energy poverty through handling energy access issues and drawing appropriate dynamic strategies that cater to the energy needs of local residential areas (Qurat-ul-Ann \& Mirza, 2021a). In following section of paper indicators 
framework to address just low carbon transition and policies assessment framework is be developed.

\section{Methods and Data}

The proposed approach is based on indicators of just low carbon transition and policies assessment frameworks described below.

\subsection{Just Low Carbon Energy Transition Indicators Framework}

In order to develop indicators framework for tracking low carbon just transition several energy indicators frameworks were reviewed (European Commission, 2017; Finland Future Research Centre, 2007; IAEA, 2005; Neves \& Leal, 2010; Onat \& Bayer, 2010; Tailor et al., 2017; Tsai, 2010). The well-developed indicator systems can facilitate the comparisons in complex situations by condensing large amounts of information into low-dimensional aggregates and allows for international comparisons by identifying benchmarks, progress achieved and underlying shifts. Therefore, the application of the indicator systems can guide policy makers to support their decisions on low carbon energy transitions (Hák et al., 2016). The analysis provided that the most suitable energy indicators framework for addressing just low carbon energy transition is Energy Indicators for Sustainable Development (EISD) framework which was developed by IAEA (2005).

Based on this framework the main indicators for analysis of the main drivers of GHG emissions and assessment of climate change mitigation policies' impact on GHG emission reduction, energy efficiency improvement, penetration of renewables and energy poverty alleviation were selected and new framework was developed.

In Table 3 indicators of new framework developed for the aim of this study- to track climate change mitigation policies impact on low carbon just transition. Below table the description of indicators is provided with the reference to methodologies and units of measurement of each indicator included in the framework.

ECO1 indicator represents Gross Domestic Product (GDP) Per Capita and is an aggregate indicator to measure the total output of the country's economy that is relevant to its population. It gives an indication of the strength of the economic activity in a country and the overall well-being of the society (European Union Open Data Profile, 2020).

ECO2 indicator represents the Gross Inland Energy Consumption per capita and is an indication of the aggregate energy consumption of the country. Gross inland energy consumption, sometimes abbreviated as gross inland consumption, is the total energy demand of a country or region. It represents the quantity of energy necessary to satisfy inland consumption of the geographical entity under consideration. Gross inland energy consumption covers: consumption by the energy sector itself; distribution and transformation losses; final energy consumption by end users; 'statistical differences' (not already captured in the figures on primary energy consumption and final energy consumption). Gross inland consumption does not include energy (fuel oil) provided to international maritime bunkers (European Union Open Data Profile, 2020). Although a high value of this indicator usually means a high standard of living and is considered an indicator of the urbanization of the society; it may as well mean an energy-inefficient society.

ECO3 is widely known as energy intensity. Energy intensity is the ratio between Gross Inland Energy Consumption and Gross Domestic Product (GDP), calculated for 


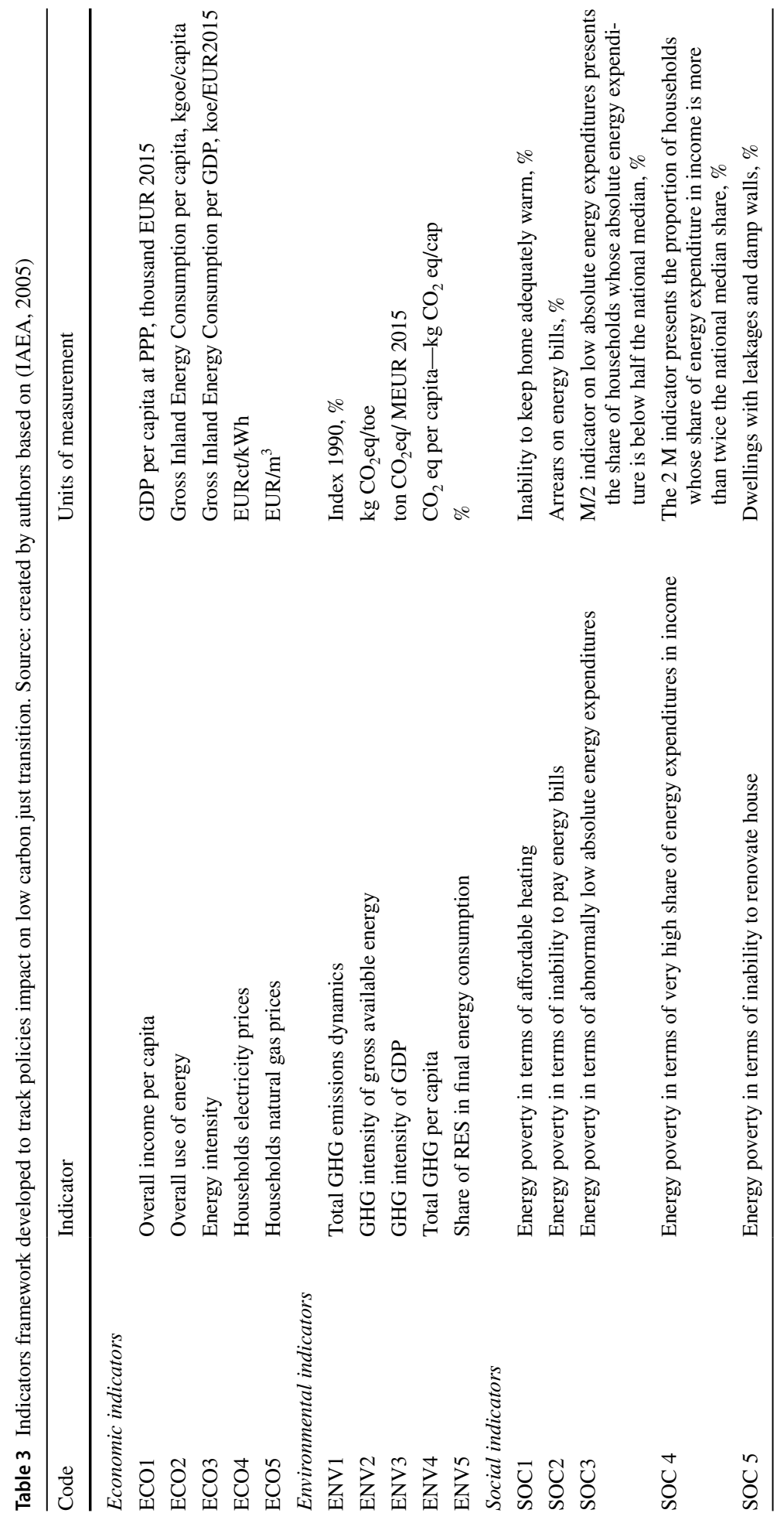


a calendar year. To monitor trends, GDP is in constant prices to avoid the impact of inflation, with a base year of 2015. Energy intensity is one of the main indicators to measure the energy needs of an economy. It is often used as an approximation of energy efficiency (EEA 2020; European Union Open Data Profile, 2020). Many factors have impact on energy intensity, like the structure of economy and its cycle, general living standards and weather conditions in the reference country.

ECO4 indicator addresses electricity prices for household consumers, band 2500-5000 kWh/yr consumption, all taxes and levies included (European Union Energy Poverty Observatory 2020a, b).

ECO5 indicator addresses natural gas prices for household consumers, band 20-200GJ consumption, all taxes and levies included (European Union Energy Poverty Observatory 2020a, b);

ENV1 indicator represents the total GHG emissions from fuel combustion The $\mathrm{CO}_{2}$ equivalent emissions of all GHG emissions from fuel combustion are summed and applied as the main indicators of progress in implementing GHG emission reduction commitments European Union Open Data Profile, 2020).

ENV2 indicator represents GHG intensity of gross available energy, expressed by $\mathrm{tCO}_{2} \mathrm{eq} /$ toe. It is commonly known as the carbonization index, which is dependent on the share of the fossil fuel in the gross available energy and the composition of the fossil fuel mix. The target is to achieve always the lower values of the carbonization index. The high values of the carbonization index in most countries are due to the nearly total dependence on the fossil fuels, namely petroleum products and natural gas, and the negligible contribution of other energy sources such as renewable and nuclear energy (European Union Open Data Profile, 2020).

ENV3 represents GHG intensity of the economy, expressed by $\mathrm{tCO}_{2} \mathrm{eq} / \mathrm{MEUR}$. The GHG intensity of GDP is an important indicator to measure the efficiency of energy consumption and carbon content of the energy supply in country(European Union Open Data Profile, 2020).

ENV4 addresses total GHG emission per capita expressed by $\mathrm{kgCO}_{2}$ eq/capita. This indicator together with the total GHG emissions and GHG emissions per \$1 GDP (PPP) were applied to measure Millennium development goals 7.

ENV5 represents the share of renewables in total final energy consumption. Many countries have set their obligations to promote the use of renewables by setting targets to increase the share of RES in their final energy consumption (European Union Open Data Profile, 2020).

As one can notice from Table 3 the main social indicators for just low carbon transition of countries are linked to energy affordability and energy poverty. As energy poverty is a multi-dimensional concept that is not easily captured by a single indicator. The approach to measuring energy poverty has been to use a suite of indicators, which should be viewed and used in combination. There are primary energy poverty indicators of which two are based on self-reported experiences of limited access to energy services based on European Union Statistics on income and living conditions (EU-SILC) data and the other two are calculated using household income and/or energy expenditure indicators based on EU Household Budget Survey (HBS) data.

SOC1 indicators addressed energy poverty in terms of inability to keep home adequately warm indicator represents the share of (sub) population not able to keep their home adequately warm, and is based on question "Can your household afford to keep its home adequately warm?" (European Union Energy Poverty Observatory, 2020a, b). 
SOC2 addresses energy poverty in terms of affordable heating. Arrears on energy bills indicator represents the share of (sub)population having arrears on utility bills, it is based on question "In the last twelve months, has the household been in arrears, i.e. has been unable to pay on time due to financial difficulties for utility bills (heating, electricity, gas, water) for the main dwelling?" (European Union Energy Poverty Observatory 2020a, 2020b).

SOC3 indicator addresses hidden energy poverty issues by indicating abnormally low absolute energy expenditures by households. The so called M/2 indicator presents the share of population whose absolute energy expenditure is below half the national median, or in other words abnormally low. This could be due to high energy efficiency standards, but it is usually indicates under-consumption of energy by households due to poverty. $M / 2$ is a relatively new indicator used to complement other expenditure and self-reported indicators. (European Union Energy Poverty Observatory, 2020a, b).

SOC4 indicator addresses energy poverty as very high share of energy expenditures in income of households. So called the $2 \mathrm{M}$ indicator presents the proportion of households whose share of energy expenditure in income is more than twice the national median share. Where income distributions are more equal, variance in energy expenditure translates to higher $2 \mathrm{M}$ shares. High variance in energy/income shares can occur due to structural differences in energy expenditure between household groups, as well as in situations where energy is often, but not exclusively, included in rent (European Union Energy Poverty Observatory, 2020a, b).

There are several secondary energy poverty indicators that are relevant in the context of energy poverty, which are not direct indicators of energy poverty itself like dwellings with leakages and damp walls. This indicator was selected for just low carbon energy transition framework to address issues linked to energy renovation needs.

SOC5 indicator addresses the energy poverty in terms of inability to renovate house. The Dwellings with leakages and damp walls indicator represent the share of population with leak, damp or rot in their dwelling, based on question "Do you have any of the following problems with your dwelling/accommodation like a leaking roof; damp walls/floors/foundation or in window frames or floor?" (European Union Energy Poverty Observatory, 2020a, b).

\subsection{Framework for Policies Assessment}

The comparative assessment of policies' impact on low carbon just transition and ranking of selected countries will be based on assessment of effectiveness of climate change mitigation policies in GHG emission reduction and delivering for other linked sustainable energy policy targets like energy efficiency increase and penetration of renewable energy sources and alleviation of energy poverty.

The main climate change mitigation policies having impact on GHG emission reduction in households were selected based on comprehensive literature review and EU policy documents (European Commission, 2015; European Commission 2019a, b, c):

- Policies to promote energy renovation of residential buildings

- Policies to promote micro-generation technologies in residential buildings;

- Policies to promote other energy efficiency improvements in households; 
The scoring of all these policies will be performed based on analysis of achieved results based on the main low carbon just transition indicators trends (1990-2018) analysis for selected countries and expert surveys in selected countries.

The expert survey is often used to get qualitative assessments of policies and measures, technologies and tools (Lu et al., 2020a; Olson, 2010; Zhang et al., 2019) especially in the areas where quantitative data is missing. The impact of climate change mitigation policies is one of these sensitive areas requiring experts in the field of energy and climate change mitigation field judgement (Kornek et al., 2020).

It is advisable to select experts from the different fields (business, state, academia) to represent broader expertise and knowledge in assessment field and opinion of different stakeholders (Lu et al., 2020a; Zhang et al., 2019).

Based on literature review (Bowen et al., 2014; Jewell \& Cherp, 2020; Kang et al. 2020; Rock et al., 2020; Streimikiene et al. 2020) and EU policy priorities (European Commission, 2015; European Commission 2019a, b, c), the following categories of criteria (indicators) were established for climate change mitigation policies assessment in households:

1. Energy efficiency improvement (decrease of energy intensity of GDP);

2. Penetration of renewables (increase of the share of renewables in final energy consumption);

3. GHG emission reduction (decrease of GHG emissions);

4. Energy poverty reduction (reduction of Inability to pay bills, Inability to keep adequate warmth).

The following five-point scale scores under each criterion were established (Lu et al., 2020b):

5-very good results were achieved by implemented policies and measures according specific criteria;

4-good results were achieved by implemented policies and measures according specific criteria;

3-moderate results were achieved by implemented policies and measures according specific criteria.

2-limited limited results were achieved by implemented policies and measures according specific criteria;

1-no results achieved by implemented policies and measures according specific criteria;

Expert panels were invited in each country for scoring of policies and measures based on available information on trends of aforementioned indicators of low carbon just transition and review and critical appraisal of Lithuanian and Greek climate change mitigation policies in households. Expert survey aimed to represent knowledge and opinion of diverse stakeholders in energy and climate change mitigation area. Specifically, 12 experts' surveys were conducted in Lithuania and 19 expert's surveys-in Greece from 21st July 2020 to 12th August 2020. Experts were contacted personally by e-mail and telephone. The main criteria for selection was long-lasting experience (not less than 10 years) in energy and climate change mitigation field based on personal contacts available. The 12 respondents in the Lithuanian survey included experts from owners of companies in the private sector (4 entrepreneurs), State administration officials with an academic title (4 policy makers) and university professors and assistants ( 4 experts from academia with academic title). The 
19 respondents in the Greek survey included experts from owners of companies in the private sector ( 7 entrepreneurs), State administration officials with an academic title (4 policy makers) and university professors and assistants (8 experts from academia with academic title).

The experts appraised the effects of the policies and measures on energy efficiency improvement; penetration of renewables; GHG emission reduction and energy poverty reduction in terms of the scores. For a certain expert, the ratings are stored in matrix. The total score for $\mathrm{i}$-th expert in assessing $\mathrm{j}$-th policy and measure according three established criteria are aggregated as follows:

$$
X_{i}^{j} \sum_{n=1}^{3} x_{i}^{n} / 3
$$

where $X_{i}^{j}$-the total score provided by of $\mathrm{i}$-th expert for assessing the impact of the $\mathrm{j}$-th policy and measure according three established criteria ( $n=3$ in our case) for specific country;

$x_{i}^{n}$ indicates the score of $\mathrm{i}$-th expert for assessing the effect of the $\mathrm{j}$-th policy and measure according to $\mathrm{n}$-th criteria for specific country;

The average score of all experts in assessing $\mathrm{j}$-th policy and measure according the three established criteria are aggregated as follows:

$$
X^{j}=\left(\sum_{i=1}^{G} x_{i}^{j}\right) / G
$$

where $X^{j}$ - the average score of all experts in assessing $\mathrm{j}$-th policy measure according to three criteria;

$x_{i}^{j}$ - the score of $\mathrm{i}$-expert in assessing $\mathrm{j}$-th policy measure according to three criteria;

G- total number of experts.

The policies and measures were further assessed based on $X^{j}$ (the average score of all experts in assessing $\mathrm{j}$-th policy measure according to three criteria). The higher is the score the better performance is achieved by policy and measure.

\section{Results of Case Studies}

\subsection{Review of Low Carbon Just Transition Indicators Development Trends in Lithuania and Greece}

Analysis of trends of the main low carbon just transition indicators in Lithuania and Greece during 1990-2018 were reviewed to track progress and underlying shift. The period 1990-2018 was selected for analysis as 1990 is base year for assessing of GHG emission mitigation achievements according to United Nations Framework Climate Change Convention (UNFCCC) and EU Energy and Climate package and framework. 2018 year or 2017 year was the most recent year where data is available (European Union Open Data Profile, 2020). The data of EU average is used like a benchmark for assessing convergence 
35,0

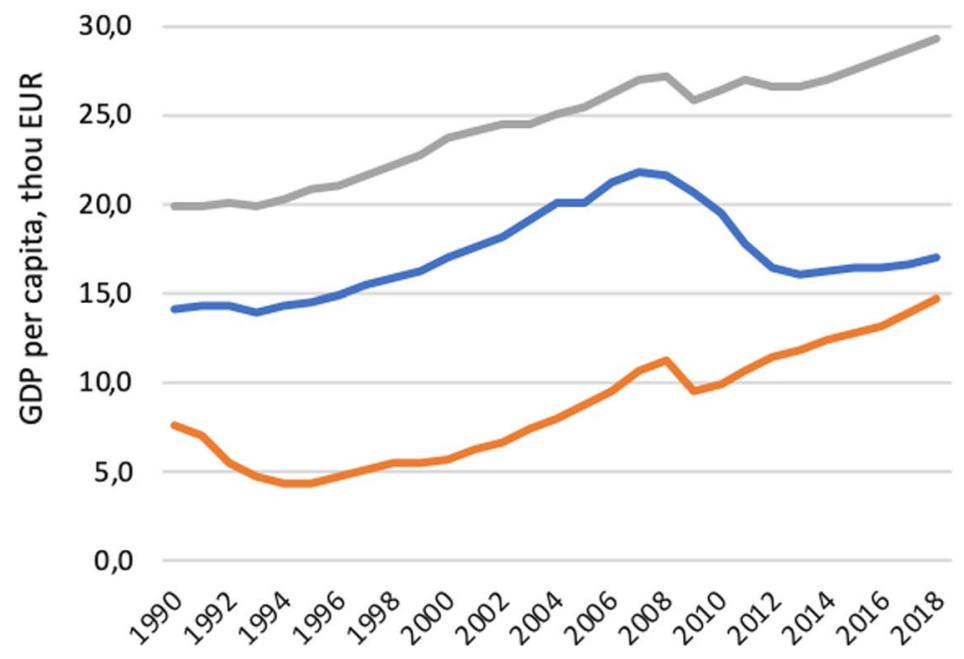

Greece

Lithua nia

EU-27

Fig. 1 Dynamics of GDP per capita (ECO1) in Lithuania Greece and EU-27. Source: (European Union Open Data Profile, 2020)

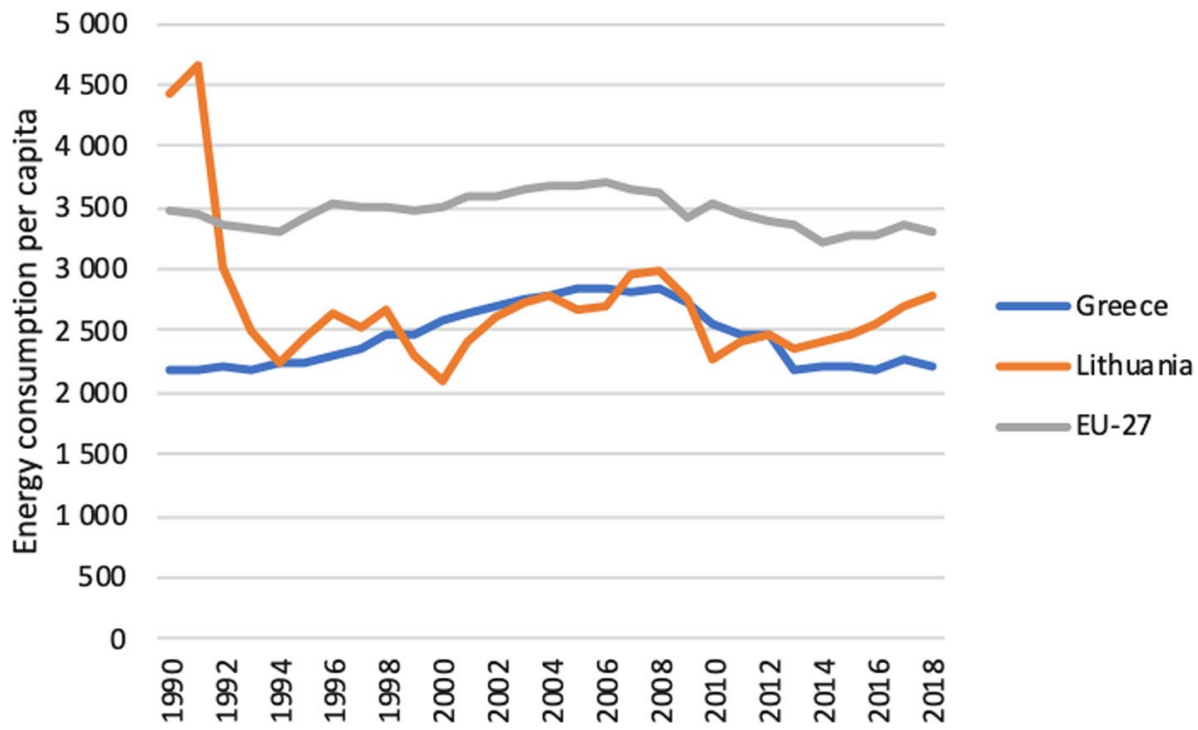

Fig. 2 Dynamics of gross inland energy consumption per capita (ECO2) in Lithuania Greece and EU-27 S. Source: (European Union Open Data Profile, 2020)

of trends and also allows to define deviation from this benchmark as advantage or shortcoming in trends of indicators development.

Dynamics of economic indicators (ECO1-ECO5) of just low carbon transition in Lithuania, Greece and EU-27 average is provided in Figs. 1, 2, 3, 4, and 5. These indicators are 


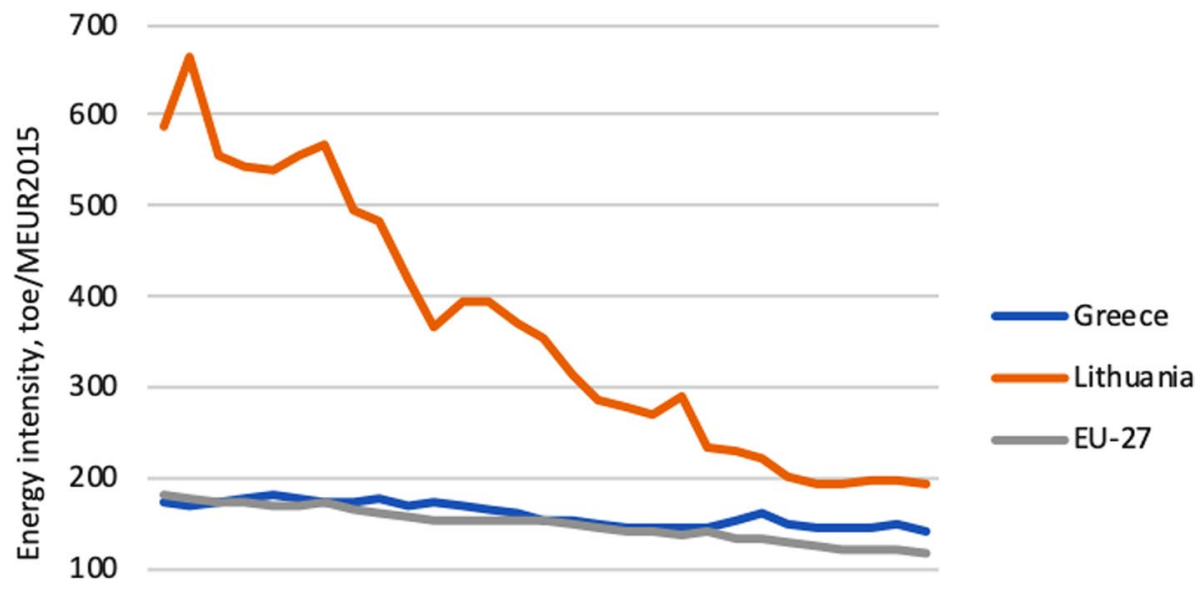

0 穴

Fig. 3 Dynamics of energy intensity (gross inland energy consumption/GDP2015) (ECO 3) in Greece, Lithuania and EU average. Source: (European Union Open Data Profile, 2020)

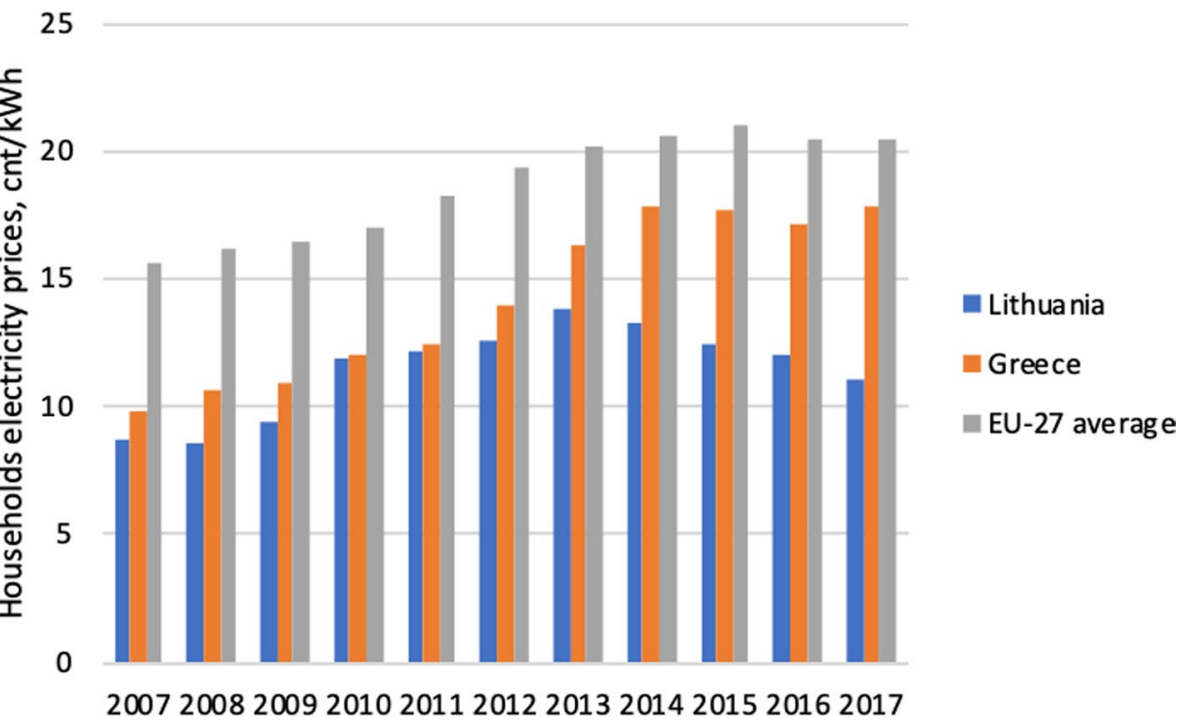

Fig. 4 Dynamics of household's electricity prices (ECO 4) in Greece, Lithuania and EU average. Source: (European Union Energy Poverty Observatory, 2020a)

closely linked with energy poverty issue and can be treated as the main drivers of energy poverty in low carbon energy transition.

Data plotted in Fig. 1 shows that Lithuania has significantly lower GDP per capita than EU-27 average though income per capita was steadily growing in the country. The 


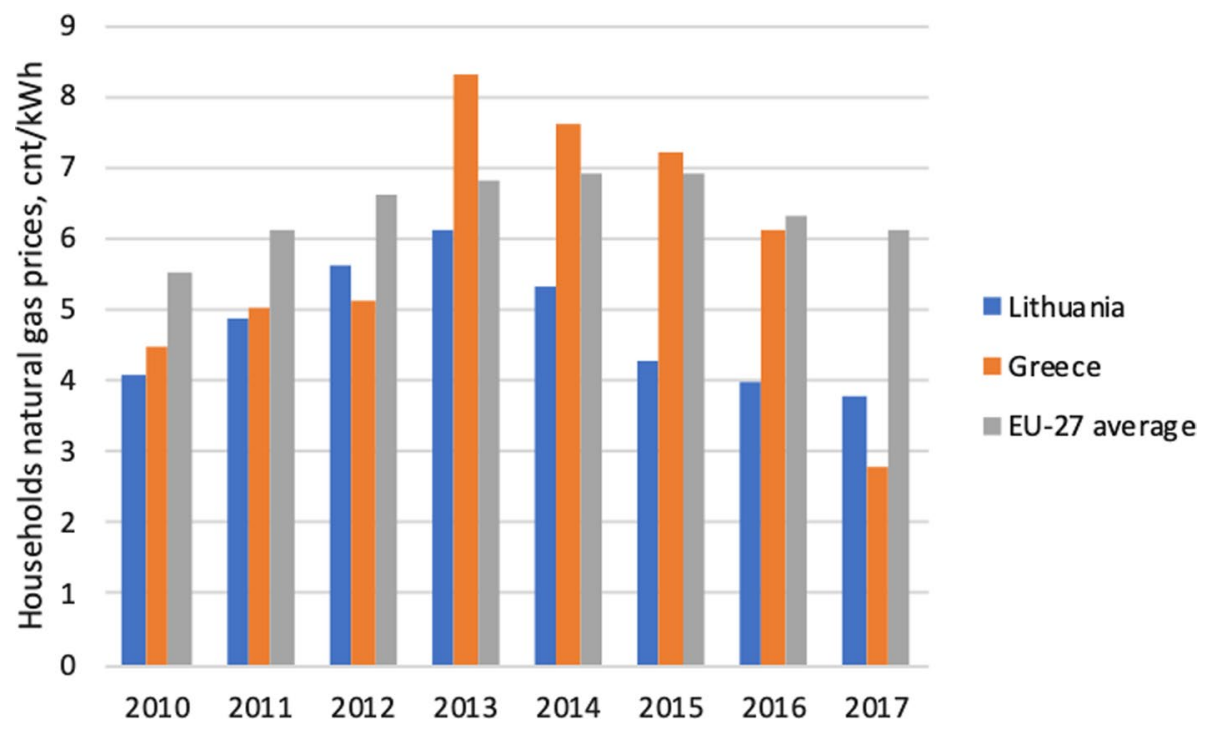

Fig. 5 Dynamics of household's natural gas prices (ECO 5) in Greece, Lithuania and EU average. Source: (European Union Energy Poverty Observatory, 2020a)

economic recession was the reason of this indicator decline in 2009. In Greece the GDP per capita is slightly higher than in Lithuania, however the impact of economic crisis was prolonged in Greece. GDP per capita is an important driving force of energy poverty alleviation and the increase of GDP per capita is necessary to ensure just low carbon energy transition.

The dynamics of another important economic indicator of low carbon energy transition-gross inland energy consumption per capita indicates big fluctuations in Lithuania (Fig. 2). The most recent trend of increase shows positive trend and drivers energy poverty reduction during low carbon energy transition. In Greece due to prolonged economic recession this indicator was decreasing showing some negative trends linked to energy poverty. In EU-27 energy consumption per capita was almost stable during investigated period and higher than in Lithuania since 1992.

Energy intensity has declined in Lithuania significantly during investigated period however it is still higher than in Greece and EU-27 (Fig. 3). In Greece and EU-27 this indicator was almost stable during investigated period showing negative trend towards low carbon energy transition.

Households electricity prices dynamics indicate constant growth of electricity prices in Greece and EU-27 though in Lithuania these prices are lower than in Greece and significantly lower than EU-27 they also were declining since 2013 showing positive trends for energy poverty reduction in Lithuania (Fig. 4).

Households natural gas prices were decreasing since 2014 in all analysed countries (Fig. 5). Especially significant decline can be observed in Greece in 2017 then the level of households natural gas prices in Greece dropped below Lithuanian prices. Therefore, positive trends towards just low carbon transition can be noticed in case of households natural gas prices.

Comparative analysis of economic indicators of just low carbon energy transition in Greece, Lithuania and EU-27 show that Lithuania distinguishes with significantly lower 
GDP per capita than EU-27 average though income per capita was growing. In Greece due to prolonged economic recession this indicator was decreasing. Energy intensity has declined in Lithuania significantly during investigated period, however it is still higher than in Greece and EU-27, though in Greece it was almost stable during all investigated period. Households electricity prices were constantly growing in Greece. Although in Lithuania these prices were significantly lower than in Greece and EU-27 they also were declining since 2013. Households natural gas prices were decreasing since 2014 in both analysed countries and EU-27.

Dynamic of the main environmental indicators of just low carbon transition is presented in Figs. 6, 7, 8, 9, and 10 below.

Lithuania has achieved the highest reduction of GHG emissions since 1990 (Fig. 6). In Greece GHG emissions were even growing until 2008 though they were reducing in Lithuanian and EU-27 average. In Lithuania since 2009 GHG emissions were almost stable. Overall, the trend of GHG emission since 1990 is positive for low carbon just energy transition in all analysed countries (Fig. 6).

GHG intensity of energy was declining in Greece and EU-27 during all investigated period, however Lithuanian GHG intensity of energy was the lowest during the same period. The positive trend towards low carbon energy transition is obvious in all investigated countries (Fig. 7).

GHG intensity of GDP was sharply declining in Lithuania and also modestly declining in Greece and EU-27 during investigated period (Fig. 8). The positive path towards low carbon transition can be noticed from these trends, though carbon intensity of GDP in 2017 in EU-27 was slightly lower than in Greece and Lithuania.

GHG emissions per capita were declining in Greece and EU-27 from 2006 however in Lithuania since 2012 the negative trend of increase can be noticed though GHG emissions per capita in Lithuania were still lower than in Greece and EU-27 average in 2017 (Fig. 9).

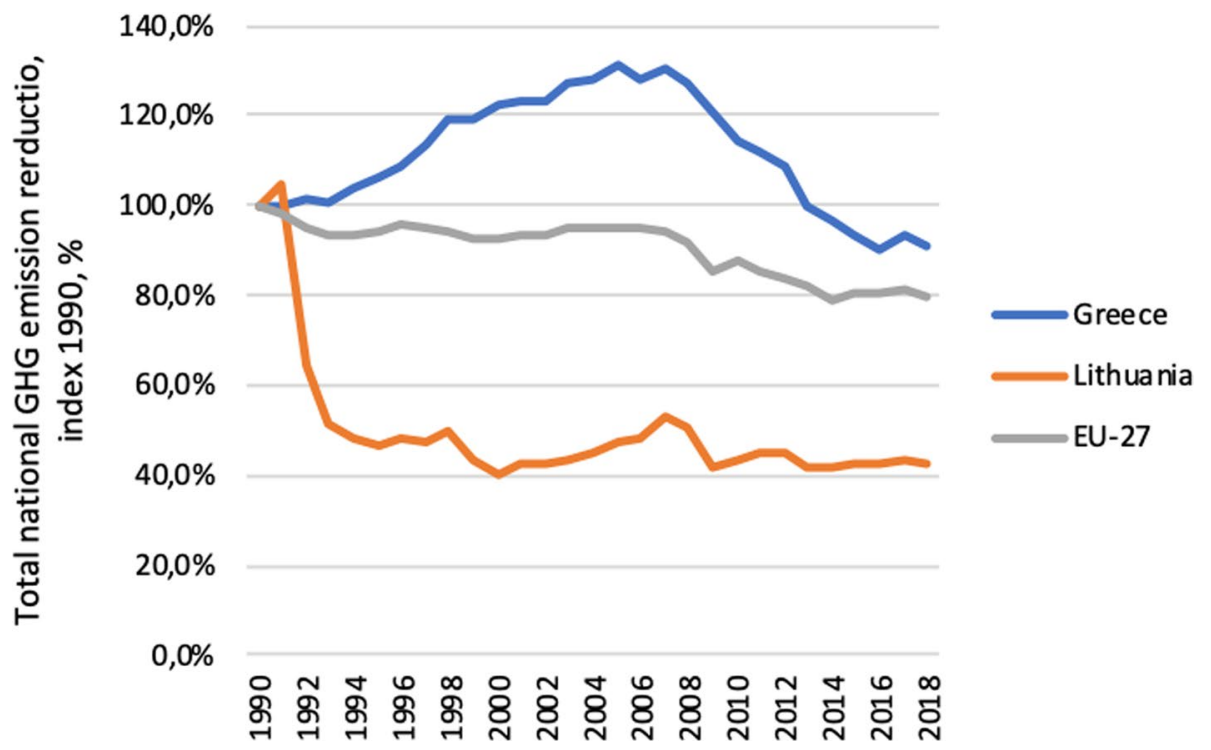

Fig. 6 Total GHG emission dynamics (ENV1) in Greece, Lithuania and EU-27, index 1990, \%. Source: (European Union Open Data Profile, 2020) 

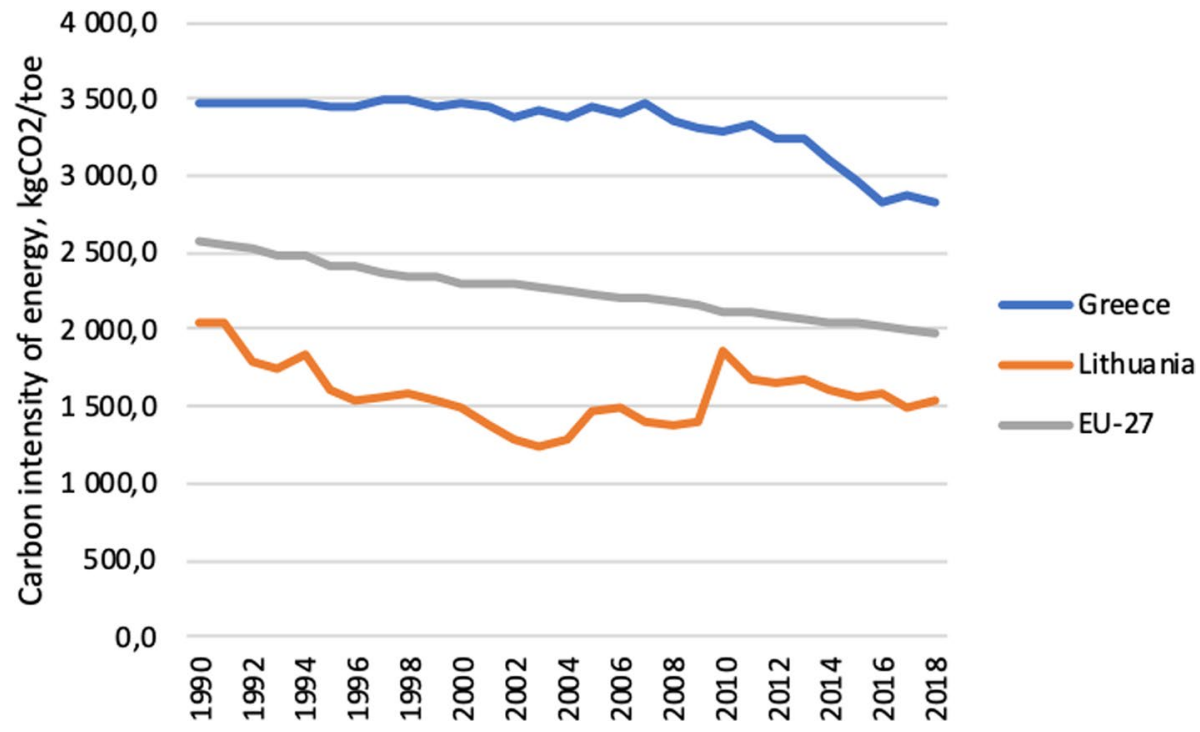

Fig. 7 Dynamics of GHG intensity of energy (ENV2), Lithuania and EU-27, kgCO2 eq/toe. Source: (European Union Open Data Profile, 2020)
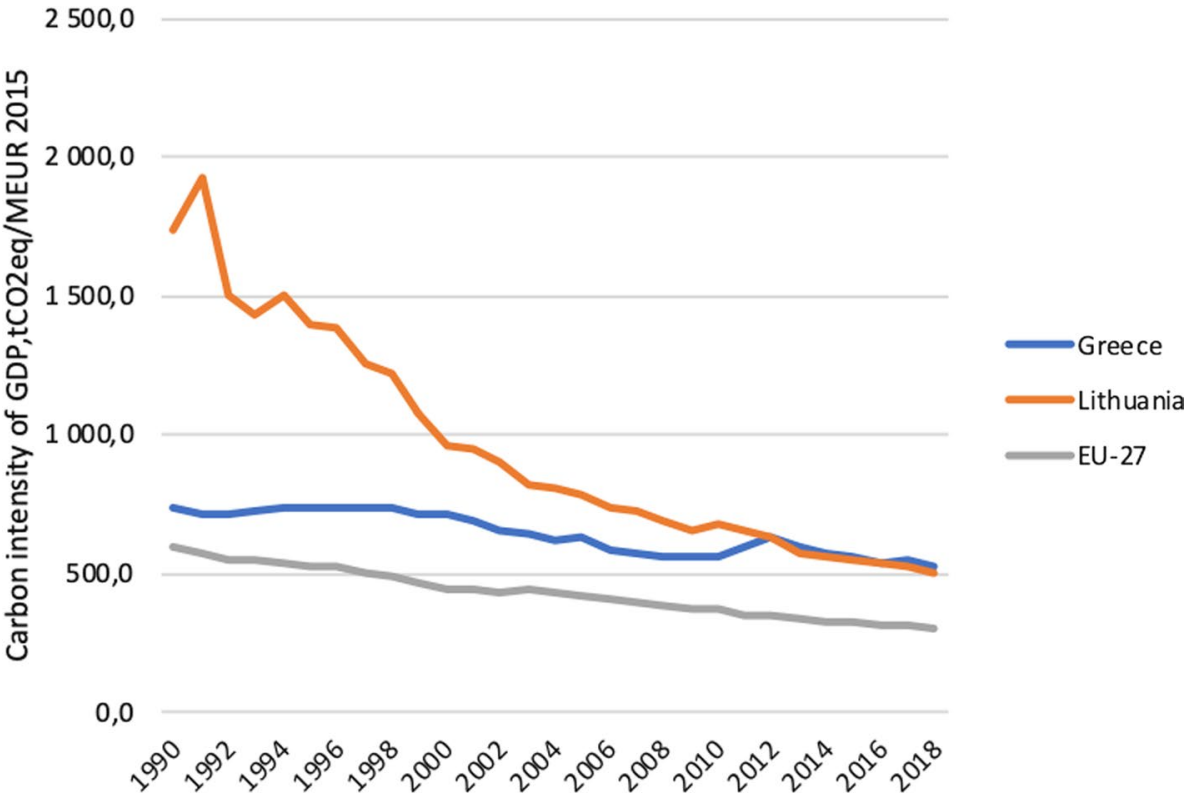

Fig. 8 Dynamics of GHG intensity of GDP (ENV3), Lithuania and EU-27, tCO2 eq/MEUR 2015. Source: (European Union Open Data Profile, 2020) 
16,0

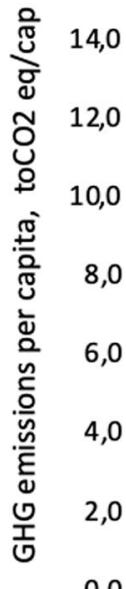

0,0

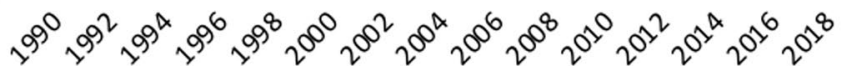

Fig. 9 Dynamics of total GHG emissions per capita (ENV4), Lithuania and EU-27, tCO2 eq/cap. Source: (European Union Open Data Profile, 2020)

$30,0 \%$

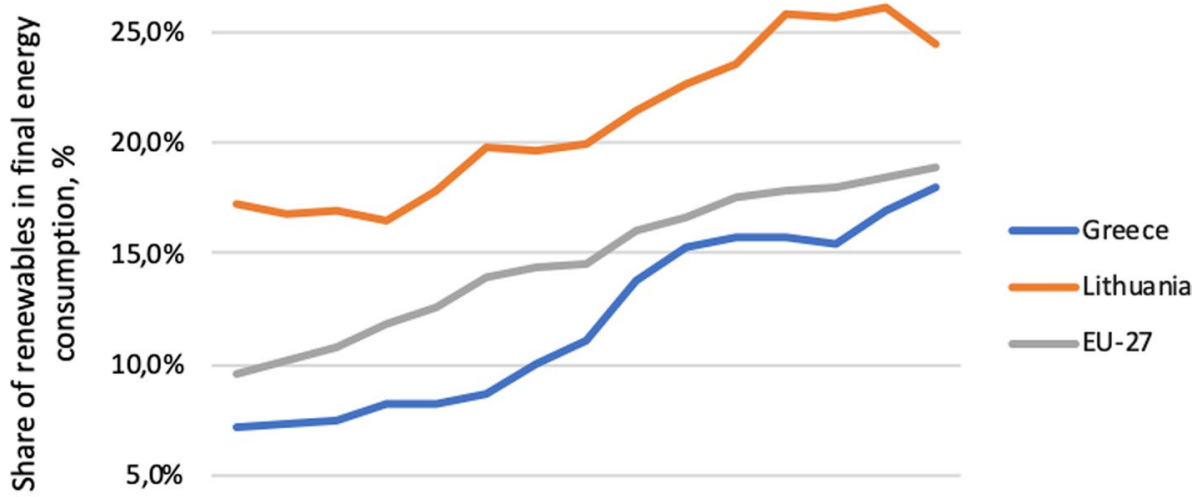

$0,0 \%$

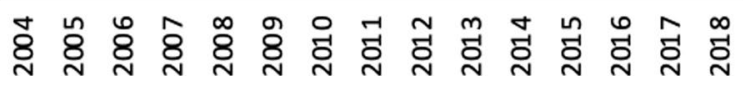

Fig. 10 Dynamics of the share of renewables in final energy consumption (ENV5), Lithuania and EU-27, tCO2 eq/cap. Source: (European Union Open Data Profile, 2020) 
The share of renewables in final energy consumption was increasing in all investigated countries and in 2017 the highest share of RES in final energy consumption was in Lithuania. All countries showing positive trends towards in low carbon energy transition (Fig. 10).

As data presented in Figs. 6, 7, 8, 9, and 10 show, Lithuania has achieved the highest reduction of GHG emissions since 1990 comparing with Greece and EU-27. In Greece GHG emissions were even growing until 2008. GHG intensity of energy was declining in Greece during all investigated period, however Lithuanian GHG intensity of energy was the lowest and almost stable during the same period. GHG intensity of GDP was sharply declining in Lithuania and also modestly declining in Greece. GHG emissions per capita were declining in Greece from 2006, though in Lithuania since 2012 the negative trend of increase can be noticed. At the same time GHG emissions per capita in Lithuania were still lower than in Greece and EU-27 average in 2017. The share of renewables in final energy consumption was increasing in all investigated countries and in 2017 the highest share of RES in final energy consumption was achieved by Lithuania.

Dynamics of social indicators which are representing energy poverty and just transition component in just low carbon transition framework in Greece, Lithuania and EU average is given in Figs.11, 12, 13, 14, and 15 below.

Dynamics of inability to keep home adequately warm in investigated countries show positive trends of decline since 2015 in Greece, since 2016 in Lithuania and since 2013 in EU-27 (Fig. 11). It is necessary to stress that the share of households unable to keep home adequately warm in Lithuania is significantly higher than in EU-27 and higher than in Greece though positive trends of energy poverty decline are obvious showing positive impact on just low carbon transition, however more Lithuania needs to put more efforts to catch other EU member states according this indicator of energy poverty.

The share of households with arrears on energy bills was declining in Greece since 2016 and in EU-27 and Lithuania since 2014. However, Greece distinguishes with very high share of arrears on energy bills comparing with Lithuania and EU-27, therefore more

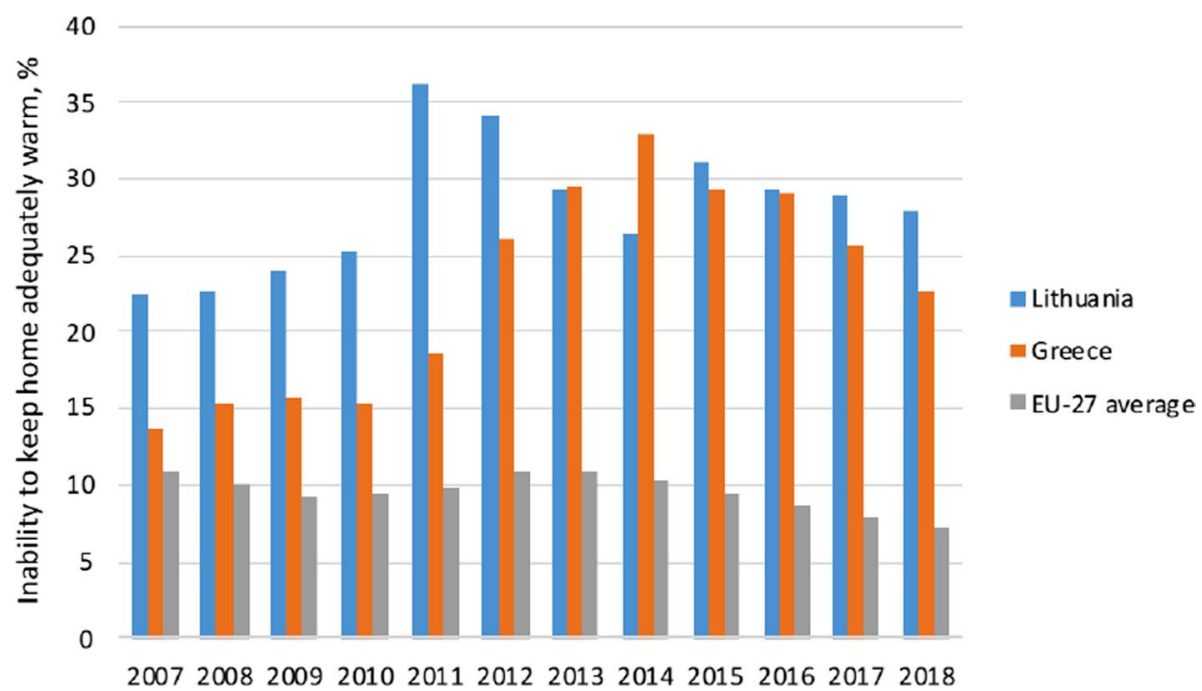

Fig. 11 Dynamics of inability to keep home adequately warm (SOC1 indicators) in Greece, Lithuania and EU average. Source: (European Union Open Data Profile, 2020) 


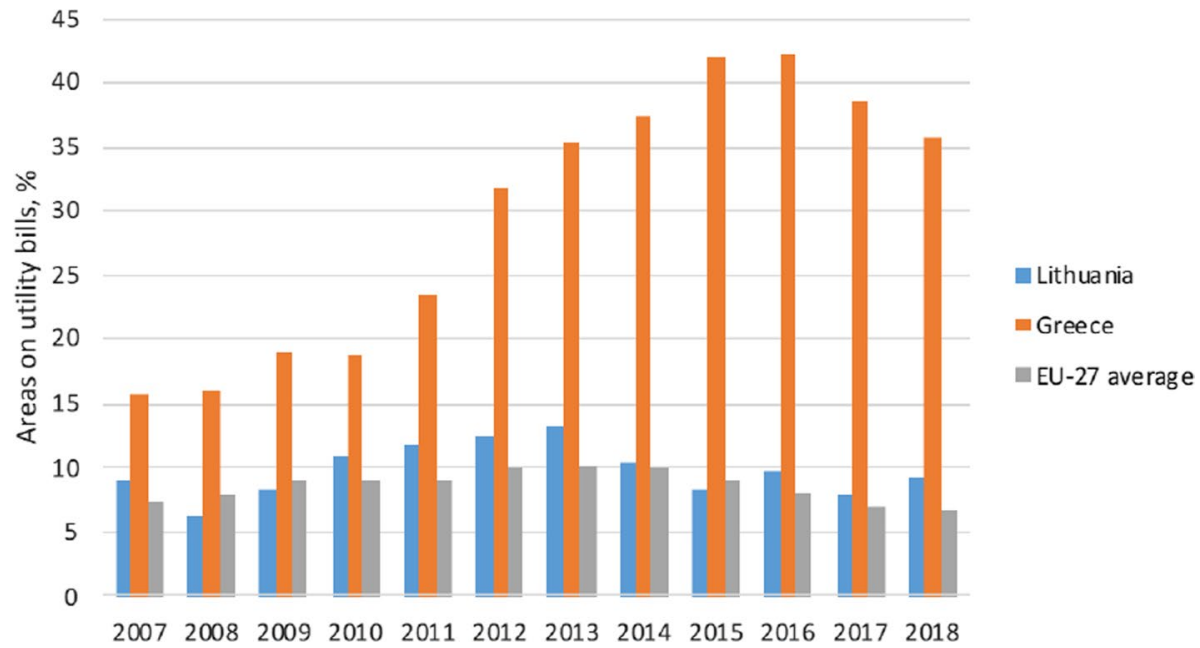

Fig. 12 Dynamics of arrears on energy bills (SOC2 indicators) in Greece, Lithuania and EU average. Source: (European Union Open Data Profile, 2020)

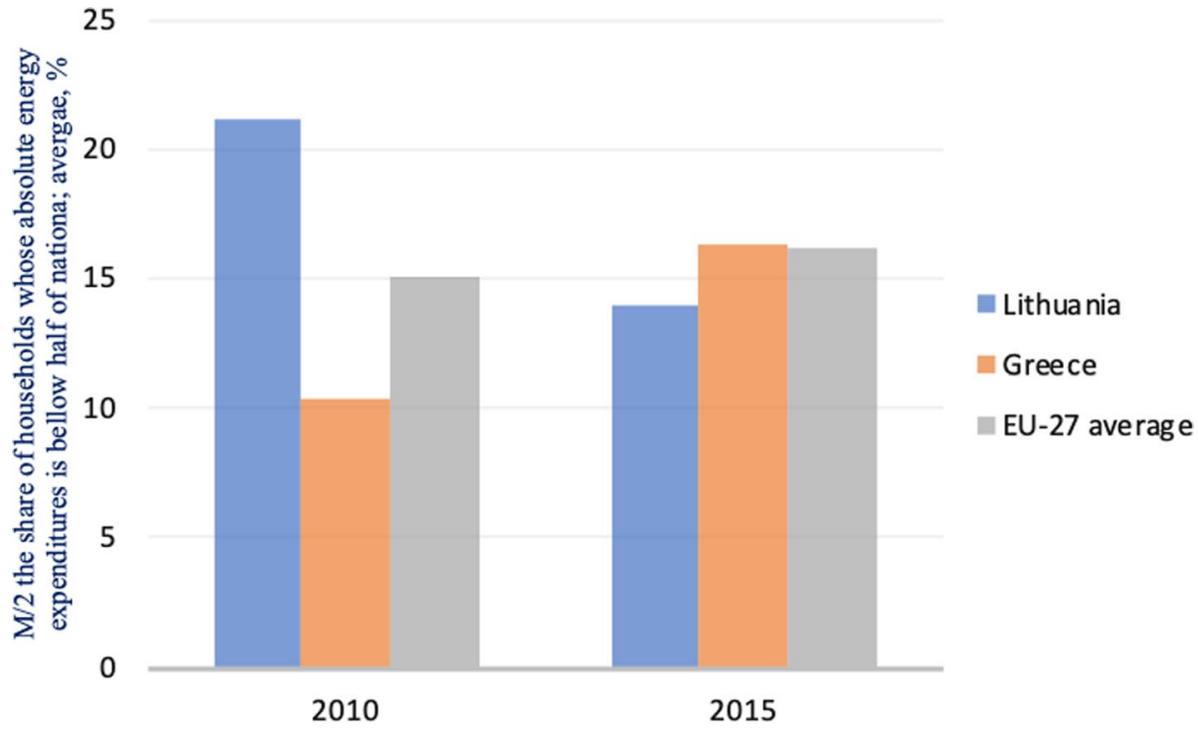

Fig. $13 \mathrm{M} / 2$ indicator (SOC3 indicators) in Greece, Lithuania and EU average in 2010 and 2015. Source: (European Union Open Data Profile, 2020)

efforts are necessary for Greece to catch other EU member states according this indicator of energy poverty (Fig. 12).

According hidden energy poverty indicator $(\mathrm{M} / 2)$ the best results were achieved by Lithuania during 2010-2015 period (Fig. 13). In Greece hidden energy poverty increased during investigated period showing negative trend towards just low carbon energy transition. In EU-27 this indicator was almost stable during investigated period. 
18

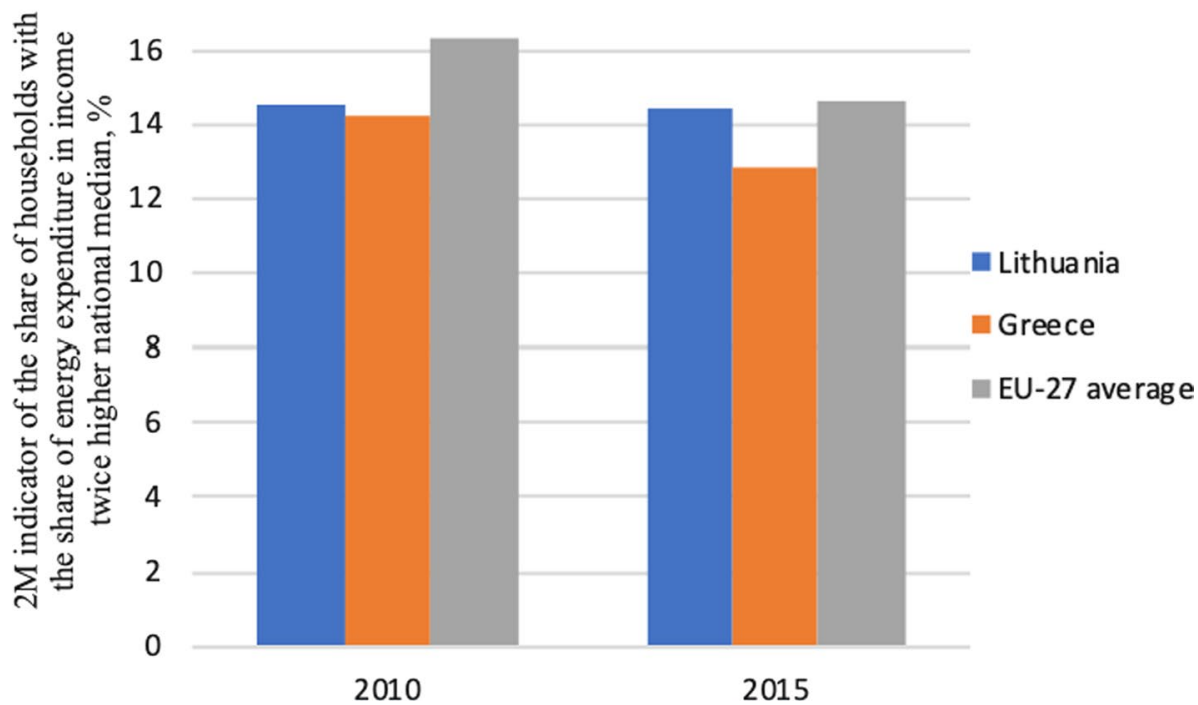

Fig. $142 \mathrm{M}$ indicator (SOC4 indicators) in Greece, Lithuania and EU average in 2010 and 2015. Source: (European Union Open Data Profile, 2020)

30

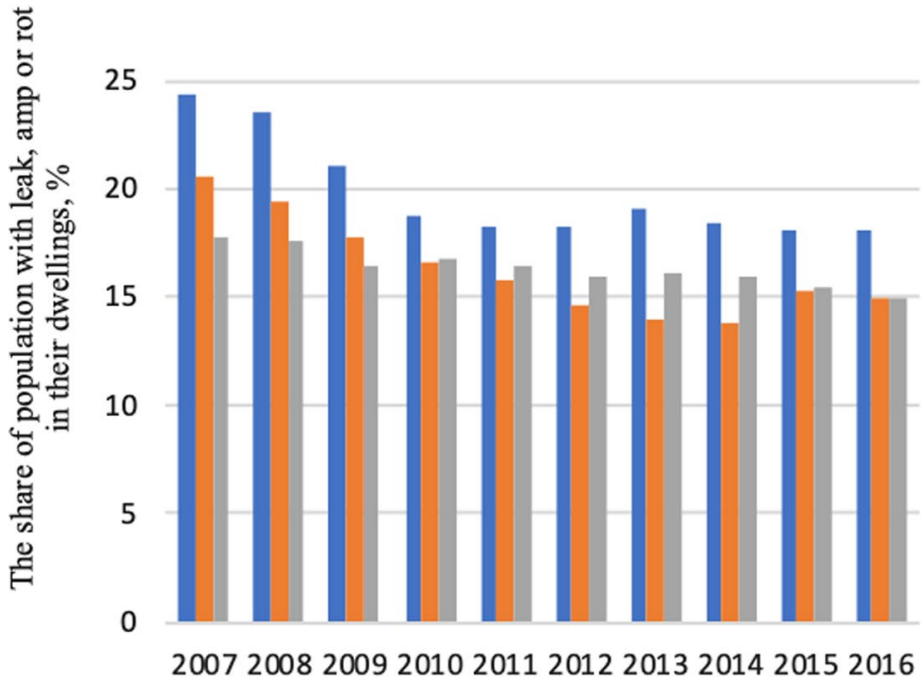

- Lithuania

Greece

EU-27 average

Fig. 15 Dynamics of the share of population living in dwellings with leakages and damp walls or rots in Greece, Lithuania and EU average. Source: (European Union Open Data Profile, 2020)

$2 \mathrm{M}$ indicator dynamics shows positive trend in Greece and EU-27 during 2010-2015 however in Lithuania this indicator remained stable during investigated period (Fig. 14). Overall, the trend of this energy poverty indicator shows quite positive trend towards just low carbon transition in investigated countries. 
The trends of indicators of dwellings with leakages and damp walls or rots since 2015 show some negative trends in Greece though in EU-27 this indicator was declining during investigated period (Fig. 15). In Lithuania positive trends of decline can be noticed until 2011 and were almost stable during 2012-2016. Overall, this indicator was the highest in Lithuania.

The data presented in Figs.11, 12, 13, 14, and 15 show very positive trends of the main social indicators decline since 2015 in Lithuania and EU-27. It is necessary to stress that the share of households unable to keep home adequately warm in Lithuania is significantly higher than in EU-27 and Greece. Though the positive trends of energy poverty decline can be seen in Lithuania, the country still needs to put more efforts to reduce this energy poverty indicator and to reach the level of other countries and EU-27 average. The share of households with arrears on energy bills was declining in Greece since 2016 and in Lithuania, however Greece distinguishes with very high share of arrears on energy bills comparing with Lithuania and EU-27. So, Greece needs more efforts to reduce this energy poverty indicator to be in the same level of other member countries. According to hidden energy poverty indicator $(M / 2)$, the best results were achieved by Lithuania during 2010-2015 period. In Greece hidden energy poverty increased during investigated period showing negative trend towards just low carbon energy transition. $2 \mathrm{M}$ indicator dynamics shows positive trend in Greece during 2010-2015 however in Lithuania this indicator remained stable during investigated period. The trends of indicators of dwellings with leakages and damp walls or rots since 2015 show some negative trends in Greece though overall this indicator is higher in Lithuania.

\subsection{Analysis of Climate Change Mitigation Policies to Address Energy Poverty in Lithuania and Greece}

Nowadays, there is need of research to addreess climate change mitigation policies and energy poverty issues in a national and international context. It is also anticipated that such a multifaceted contextualization to support electricity providers to dedicate their future products and services so as to keep their industrial and domestic customers satisfied (Drosos et al., 2020). In this respect, it is noteworthy to signify the following climate change mitigation policies and measures able to address energy poverty:

1. Financing and funding of improvements in the energy situation of households is the most popular way to solve energy poverty problems by facilitating the improvement of building insulation, cooling and heating systems, household appliances and increased use of renewable energy technologies. There main financing and funding mechanism can be done through Tax incentives, Grants and Loans, Public funding Private funding, Public-private partnerships or levies (Electricity levy, Natural gas levy or Heating oil levy. It is necessary to stress that electricity levies that are used to fund solar panels can have regressive impacts on energy poverty as energy poor households spend a relatively larger share of their income to pay these levies, while they are usually not applying for solar panels funding.

2. Energy audits are also preferable climate change mitigation measure as it allows to ensure energy and costs savings in energy poor households. The visits to energy vulnerable households are able to provide direct advice on how to improve their specific situation linked to energy consumption (Boemi et al., 2017; Papada \& Kaliampakos, 2020). These measures are successful in reaching households, because they are often 
carried out in cooperation with other social organisations, for example social workers or health professionals.

3. Information and awareness are measures that indirectly facilitate energy poor households to improve their situation by providing advice, information or education how to save energy, apply curtailment behavior practices (Balouktsis \& Kekkeris, 2013; Boemi et al., 2017; Theodosiou \& Ordoumpozanis, 2008).

There are three additional policies and measures dealing with energy poverty, however these measures do not address the structural problems of energy vulnerability and are effective in lowering the burden of energy costs of households in the short-term, but do not provide long-term solutions to the problem. These measures also have negative impact on climate change mitigation efforts.

1. Disconnection protection measures provides protection against energy supply disconnection for vulnerable households, often in colder months during wintertime (Boemi et al., 2017; Papada \& Kaliampakos, 2020).

2. Social support provides general income support for households to cover more general expenses such as housing or living costs, including energy costs.

3. Financial or fiscal assistance to reduce energy bills can be given in two ways. Social tariffs lower the energy bill that has to be paid by households, while energy bill support provides financial assistance to pay the energy bill. Fiscal assistance in terms of reduced taxes (VAT) is mainly applied for district heating and electricity.

In approaching the aforementioned climate change mitigation policies in households, a multifaceted literature overview of residential buildings in Lithuania and Greece was conducted. (Table 4).

The comparative analysis of energy poverty alleviation policies in Greece and Lithuania showed few important differences, which are mainly linked to long-term poverty alleviation policies. In Lithuania policies targeting energy poverty alleviation include short-term energy poverty reduction measures like disconnection protection; financial assistance to reduce energy bills by reduced VAT to district heating for all residents and compensations on heating, cold and hot water costs for households with low income. In Greece main short-term policies are quite similar: use of Social Residential Tariffs introduced to protect vulnerable groups of population and disconnection protection.

Yet, Greece distinguishes with limited long-term energy poverty alleviation measures especially in the field of Financing and funding of improvements in the energy situation. Measures of Information and awareness are dominating in the country. Conversely, there are diverse long-term energy poverty alleviation policies implemented in Lithuania like financing measures under Modernization programme for promotion of RES in residential buildings; soft loans with fixed 3\% interest rate for promotion of energy efficiency and use of RES in residential buildings from Multi-apartment Buildings Renovation Programme, promotion of renewables by Feed-in tariff for Photovoltaics in residential houses and promotion of prosumers of renewable energy sources based on Lithuanian legal acts. 


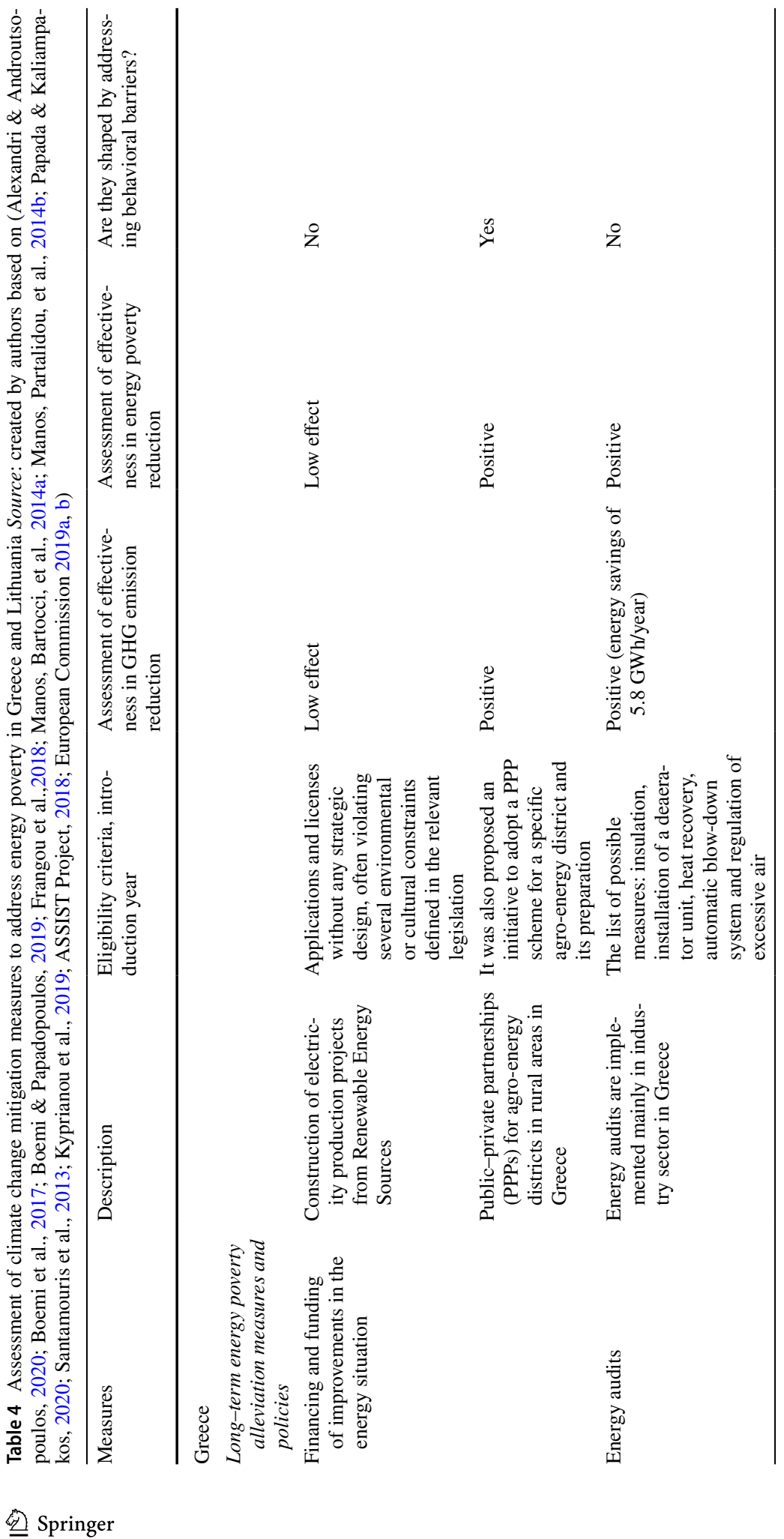




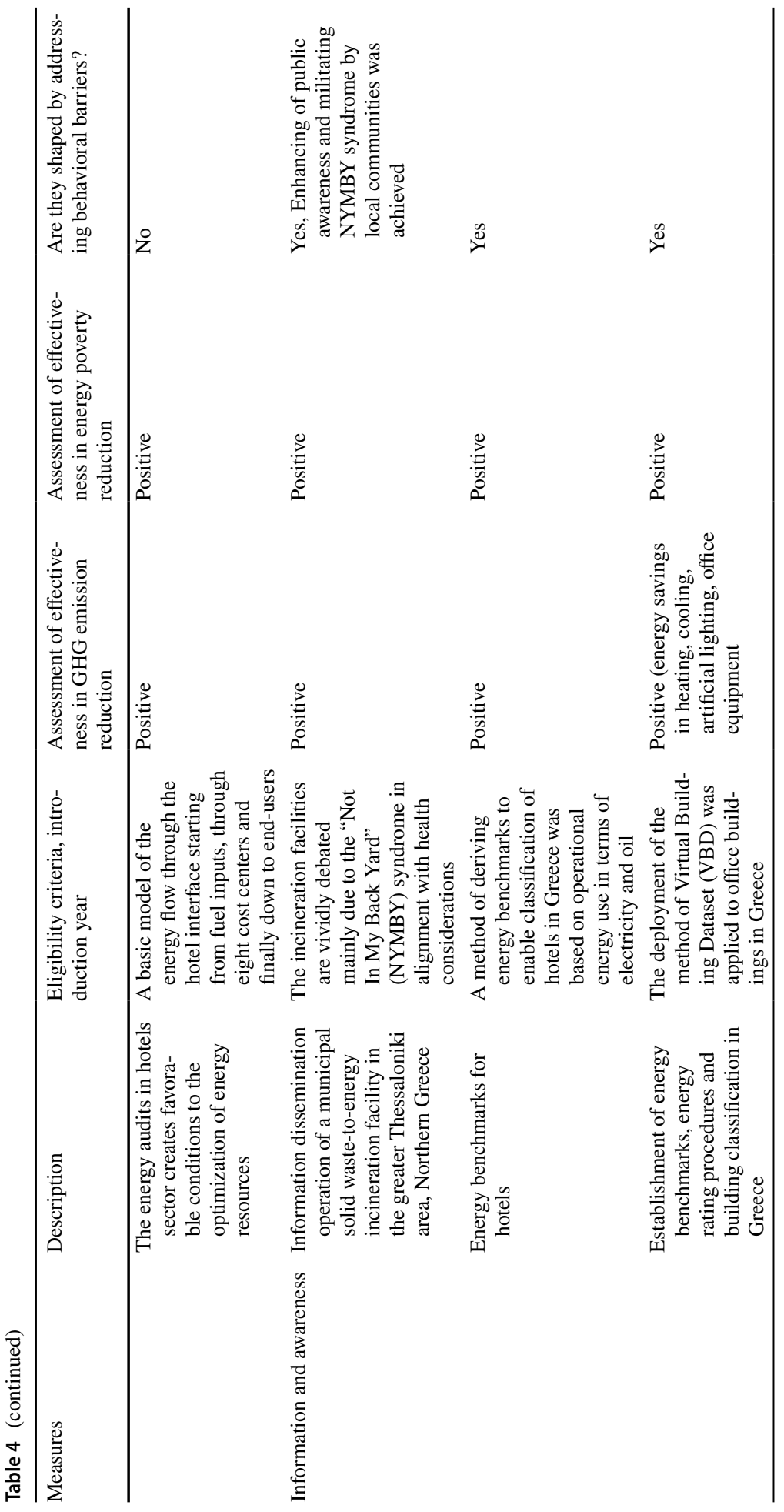




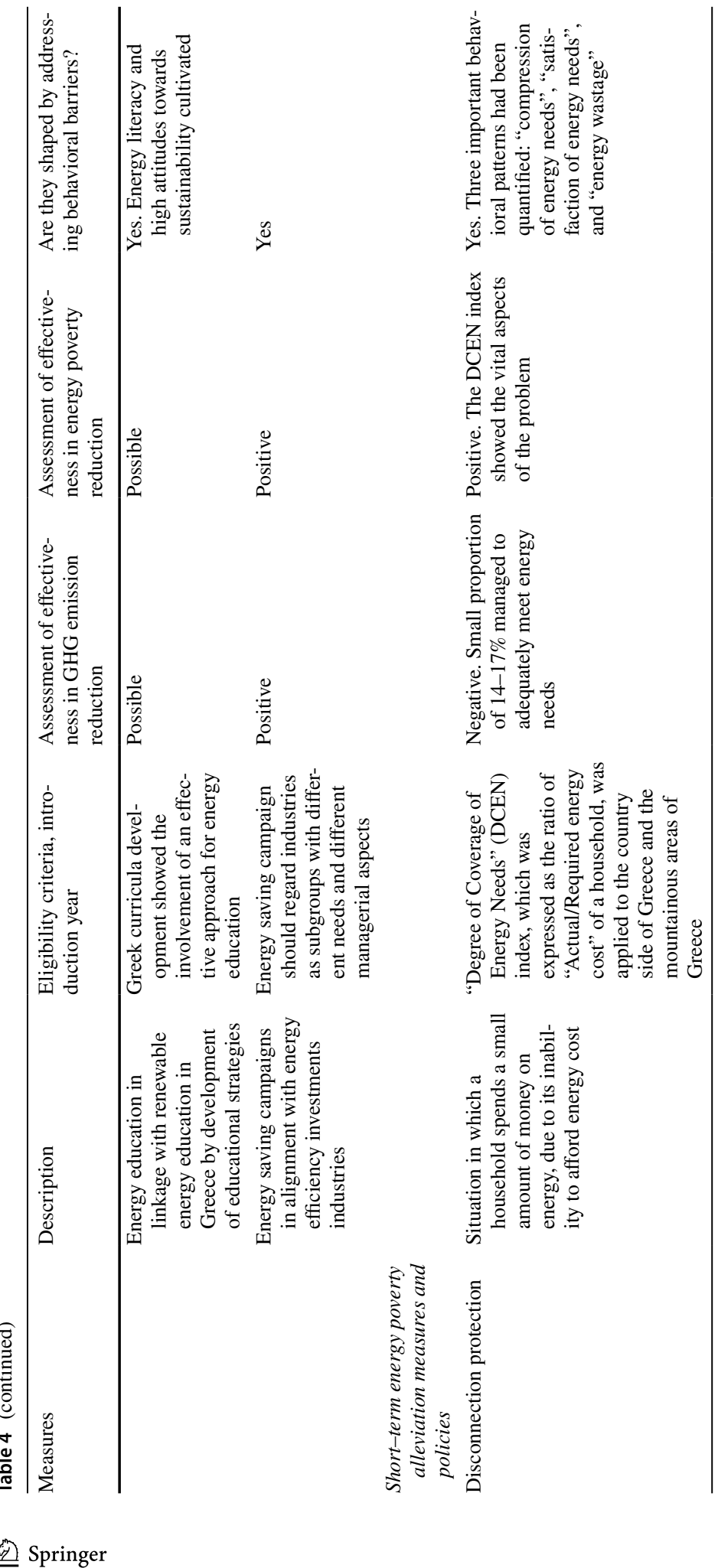




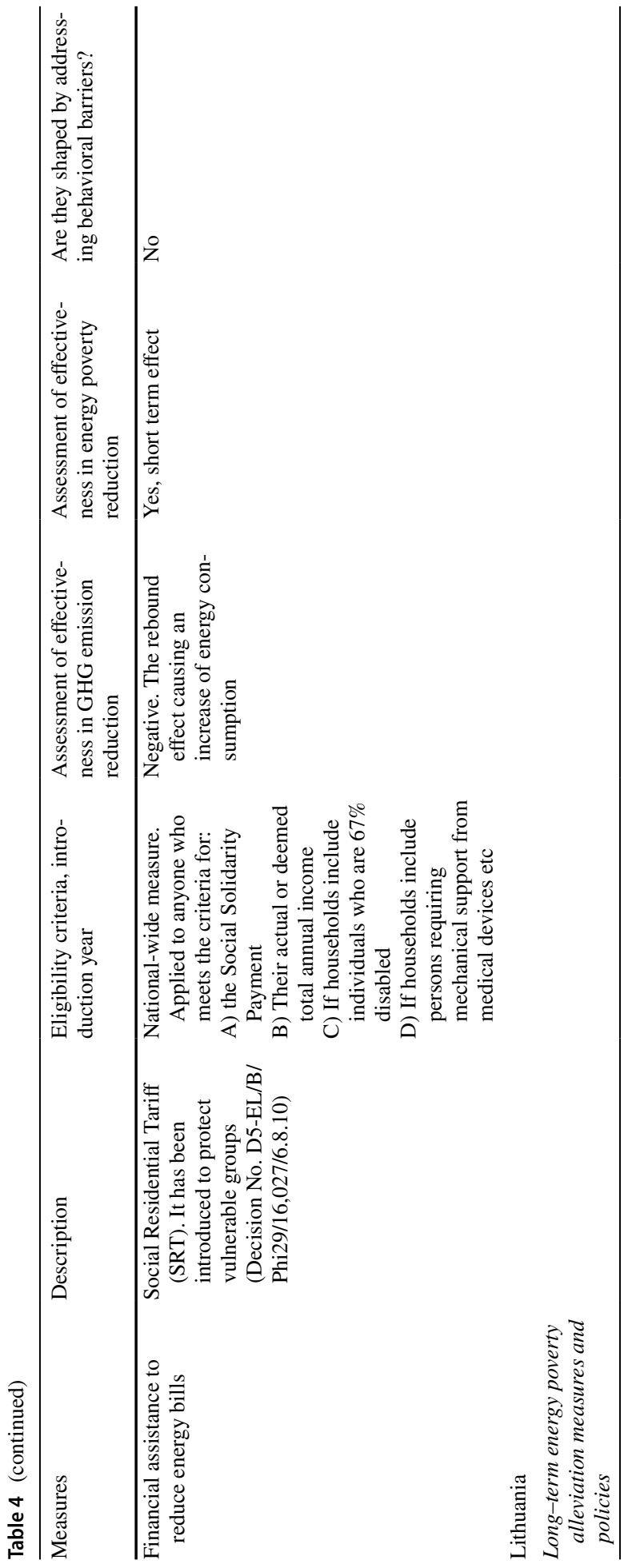




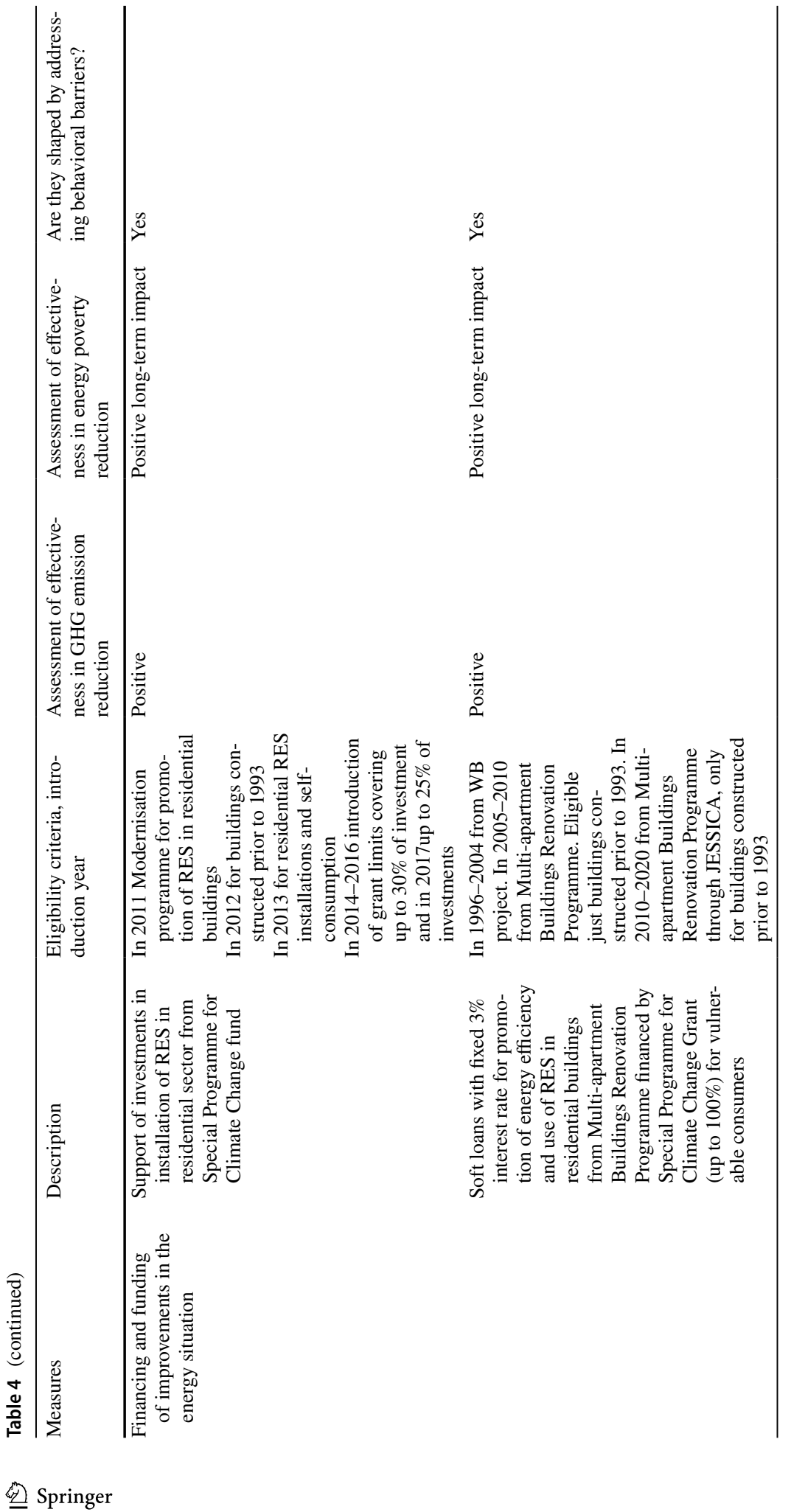




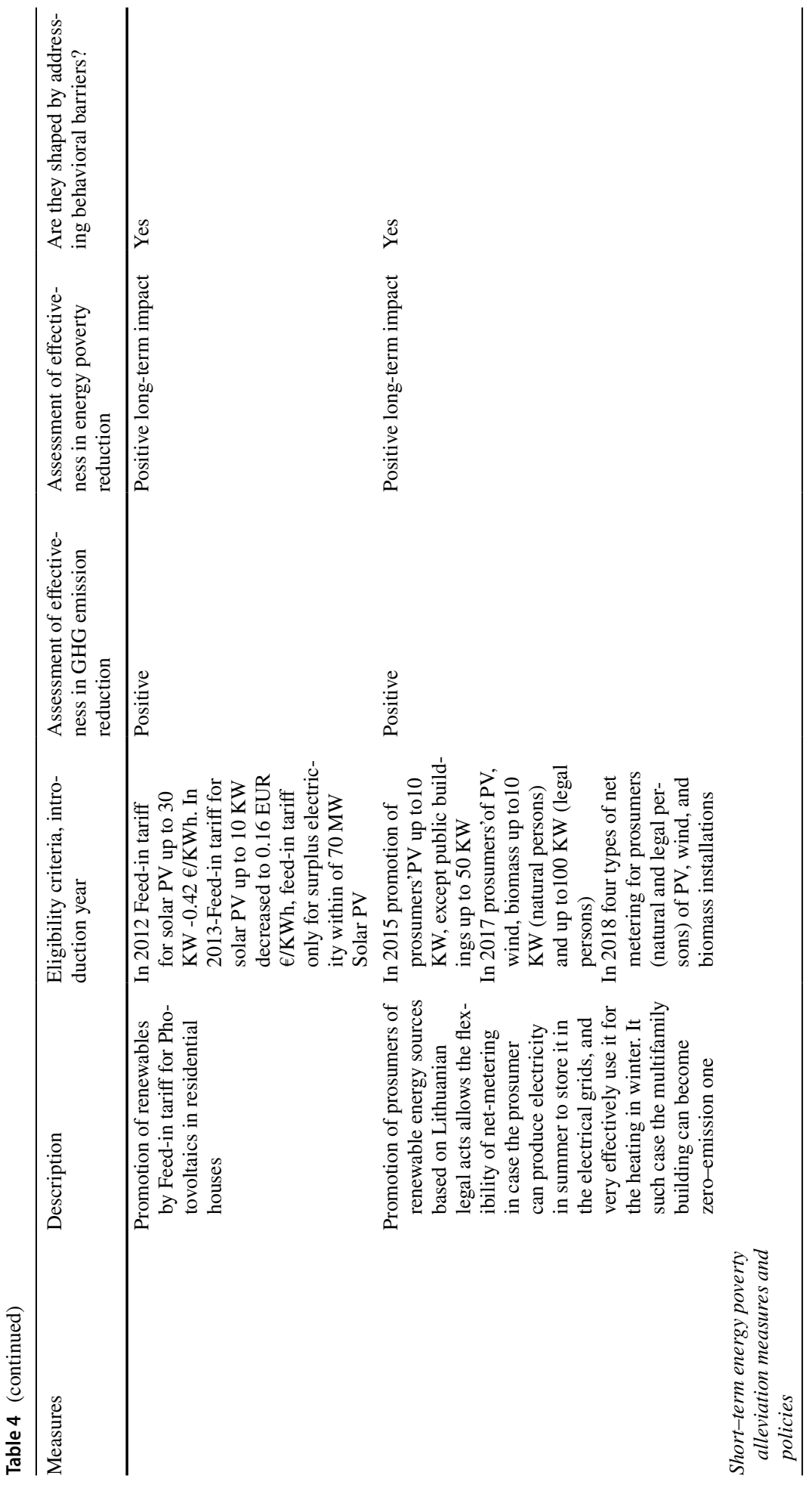




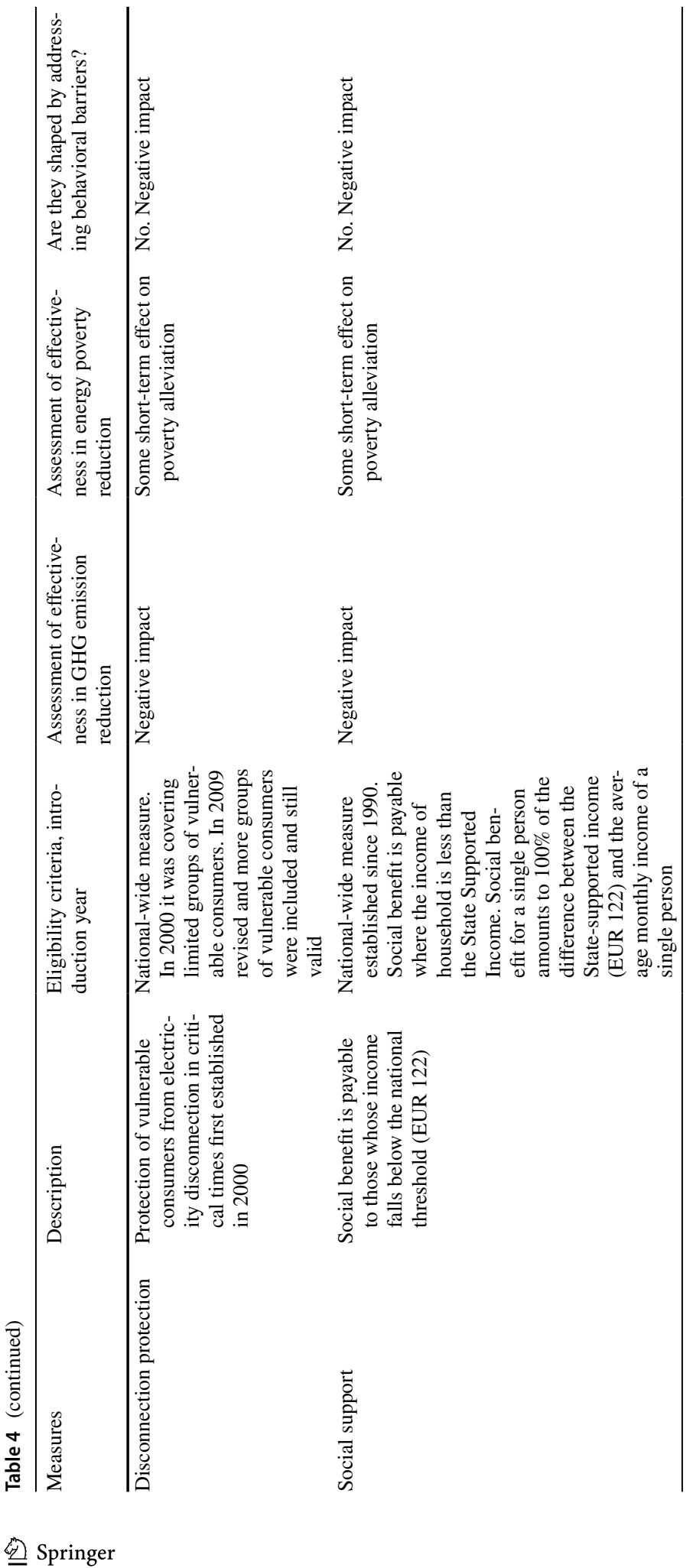




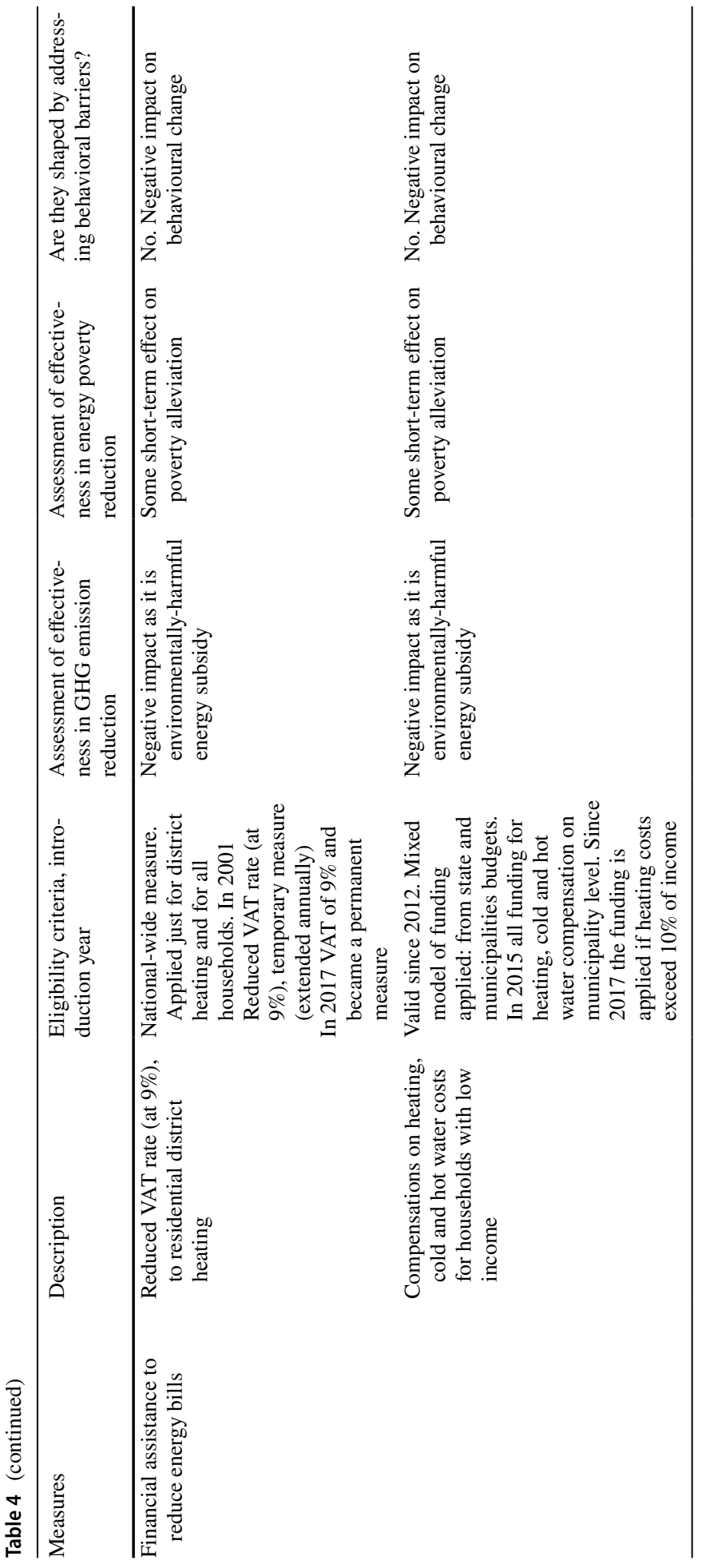




\section{Discussion of Results}

Expert survey was conducted in each country in order to assess the effectiveness of climate change mitigation policies in the country based on four criteria (energy efficiency improvement; penetration of renewables, GHG emission reduction, energy poverty reduction) and ranking scores described in Sect. 4.2.

In Table 5 results of experts' survey in Greece are provided.

Based on Table 5 at the Greek context and the outcomes yielded in the fields of "overall impact" and "means", it is denoted that the policies to promote other energy efficiency improvements in households are slightly more advantageous, comparing to that of promoting micro-generation technologies in residential building, and that of promoting energy renovation of residential building. It is also important to note that the highest and the lowest rates were reported at the policies to promote other energy efficiency improvements in households, given by a state administration-respondent for the criterion "penetration of RES" (4.5/5.0) and by a business-respondent for the criterion "energy poverty reduction" (1.7/5.0). From this wide spread of rates given by the state administration and the business experts, it is also stressed out from the other fields and criteria surveyed, it can be inferred that there is a poorly connectivity developed between advancements driven from academia and their applicability prospects at technological (Kyriakopoulos et al., 2019), organisational (Kapsalis et al., 2019), environmental (Zamparas, Kapsalis, et al., 2019), business and state administration (Lazarou et al., 2018), domains. However, taken into consideration that both these fields of state administration and business are offering their funding aid to a large-scale materialization of these academic advancements, it is crucial the nurturing of a close collaborative environment among all three fields (business, state administration, academia) studied. Regarding the ordering profile of the policy of energy poverty reduction among the three fields of expertise it can be concluded that the highest rate was noted at the promotion of "other energy efficiency improvements in households", followed by the promotion of "micro-generation technologies in residential buildings", and then, the promotion of "energy renovation of residential buildings". Besides, these policies are considering insufficient thermal insulation, low income, and high energy costs, as the main constraints resulting from the continuing economic recession in Greece.

In Table 6 results of experts' survey in Lithuania are provided.

As one can see from Table 6 the policies to promote energy savings in buildings were assessed by experts at highest scores in terms of providing to just low carbon transition in Lithuania and delivering the best results in energy savings, penetration of renewables, GHG emission reduction and energy poverty alleviation. This is fully understandable as energy promotion of energy renovation of buildings has huge energy conservation potential and allows significant reduction of GHG emission and provides additional benefits like savings of energy expenditures and increased of living comfort in renovated houses together with reduction of energy poverty indicators. In Lithuania implemented Multi-apartment Buildings Renovation Programme showed great success and experts evaluated this policy and measure with high score.

The policies to promote renewables were evaluated by expert with the lowest total mean score showing that these policies currently implemented in Lithuania have not provided for good results towards just low carbon transition first of all because implementation of renewables in households in Lithuania is in initial stage and requires additional support due to low awareness and high costs of renewable energy microgeneration technologies. The policies and measures to promote energy efficiency in households not linked with 


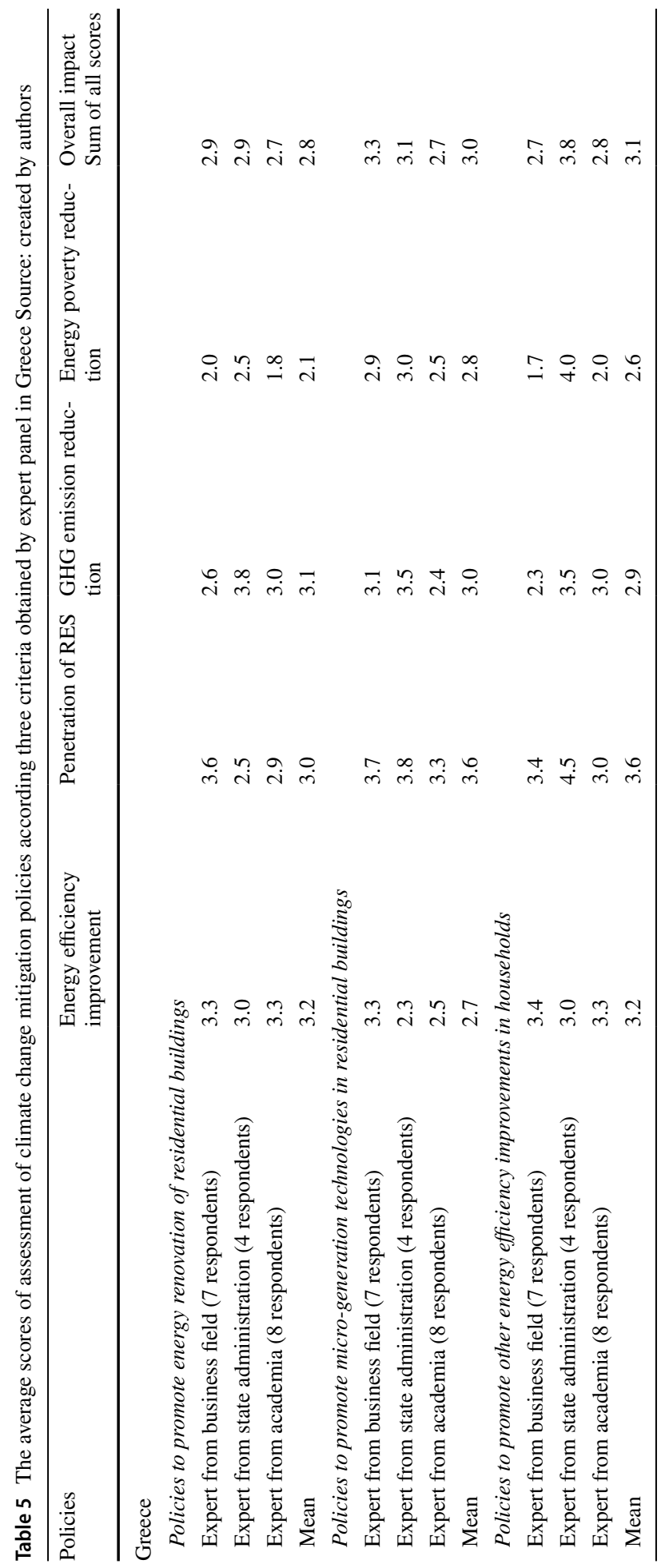




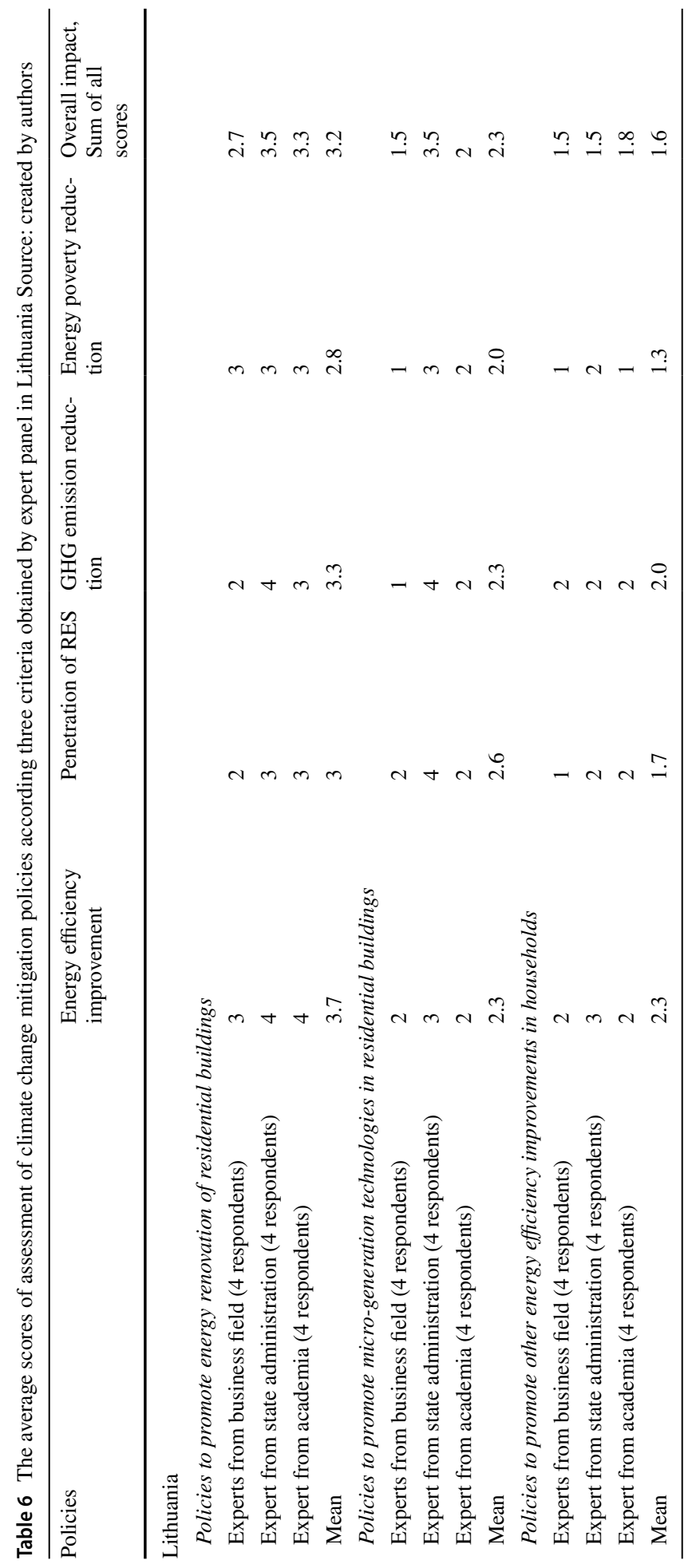


renovation of apartment buildings received very low scores by Lithuanian experts due to the facts that these measures are mainly linked to behavioral changes and sustainable energy consumption behaviors which need additional measures to overcome main behavioral barriers like asymmetric information, bounded rationality, split incentives etc.

\section{Conclusions and Future Research Areas}

Just low carbon transition indicators framework was developed based on analysis of scientific literature by addressing the gap of knowledge in tracking low carbon energy transition. The created indicators framework consists of 15 indicators addressing economic, social and environmental issues linked to just low carbon energy transition.

Economic indicators are selected as the main driving force indicators for just low carbon transition: GDP per capita, energy intensity of economy, overall energy consumption per capita and household's energy prices (electricity and natural gas). The main environmental indicators of just low carbon transition are driving force indicators like the share of renewables in final energy consumption and state indicators like GHG intensity of energy; GHG intensity of GDP, GHG emissions per capita and total GHG emission reduction. The main social indicators of just low carbon transition were selected to address state of energy poverty, vulnerability and justice in just low carbon transition and include such state indicators as inability to keep home adequately warm; arrears on energy bills, dwellings with leakages and damp walls or rot, M2 and M/2 indicators.

The developed just energy transition indicators framework was applied in Greece and Lithuania to analyse the main trends of just energy transition and to identify the main problems and provide policy recommendations.

The comparative analysis of the main trends of economic indicators of low carbon just transition in Lithuania and Greece revealed that economic indicators which are the main drivers of energy poverty reduction in Lithuania are showing more favorable trends comparing to Greece. However, it is necessary to stress, that the achieved level of these indicators is Lithuania is lower than in Greece and also EU-27 average. One exclusion is energy prices which were significantly lower in Lithuania than in Greece and EU-27 during all investigated period and were also declining. Environmental indicators of just low carbon transition in Lithuania also showed very positive trends and achieved level indicates significant progress towards low carbon energy transition. Country has achieved the highest reduction of GHG emissions since 1990, reached lowest GHG intensity of energy and highest share of renewables in final energy consumption comparing with Greece and EU-27 and also it has the lowest GHG emissions per capita though the trend of increase can be noticed due to decline of population.

Analysis of social indicators in Lithuania showed very positive trends of decline since 2015 though the share of households unable to keep home adequately warm in Lithuania is significantly higher than in EU-27 and higher than in Greece. Greece distinguishes with very high share of arrears on energy bills comparing with Lithuania and EU-27 and also with negative trends of almost all social indicators.

The comparative analysis of energy poverty alleviation policies in Greece and Lithuania showed that countries have implemented similar short-term policies like protection of vulnerable groups of population by reduced energy tariffs and disconnection protection. However, Greece distinguishes with quite limited long-term energy poverty alleviation measures especially in the field of financing and funding of improvements in the 
energy situation. Measures of information and awareness are dominating in the country. Conversely, there are diverse long-term energy poverty alleviation policies implemented in Lithuania like well-developed financing measures to promote energy renovation and RES technologies in residential buildings.

Assessment of climate change mitigation policies in households based on the main criteria of just low carbon transition: energy efficiency improvement, penetration of renewables, GHG emission reduction, and alleviation of energy poverty conducted by experts in Greece and Lithuania also revealed different results. In Lithuania the policies to promote energy savings in buildings were assessed by experts at highest scores in terms of providing to just low carbon transition and with the lowest total mean score in Greece. The policies to promote energy efficiency improvements in households were evaluated by Lithuanian experts with the lowest total mean score showing that these policies currently implemented in Lithuania have not provided for good results towards just low carbon transition. However, these policies received the highest scores in Greece indicating that according to expert's opinion, they are delivering the best results in energy savings, penetration of renewables, GHG emission reduction and energy poverty alleviation therefore fit the best the just low carbon transition targets.

The main policy implications of conducted study are linked with recommendation of new policies. Policies and measures to promote energy efficiency in households requires more attention by Lithuanian policy makers as these policies and measures were evaluated by experts with the lowest total according to all criteria showing the 'efficiency gap' which can be largely explained by a combination of market and behavioral failures. Nudging or boosting policies can help to overcome important behavioral barriers of energy saving in households like asymmetric information, bounded rationality, split incentives etc. The policies to promote renewables in Lithuanian households need also more attention by policy makers as use of renewable energy micro generation technologies is currently in initial stage and requires additional support due to low awareness and high costs of renewable energy microgeneration technologies therefore, new financial support and awareness rising mechanisms are necessary. Policies and measures to promote renovation of residential buildings needs to be strengthened in Greece based on expert evaluations and good Lithuanian practices. Having in mind negative trends of economic and social indicators of low carbon just energy transition framework in Greece, the additional measures to promote energy renovation of residential buildings would allow country to achieve win-win solutions: energy savings, GHG emission reduction and energy poverty alleviation together with economic growth and increase of employment.

The limits of this study are mainly linked to the subjectivity in analysis of policies and measures performed by experts. The future research is necessary in order to integrate some additional policy analysis tools like decomposition of GHG emissions by sectors and the main drivers (GDP per capita, energy intensity of GDP and carbon intensity of energy supply and based on the Kaya identity. These more robust techniques like fuzzy-Monte Carlo simulation to address uncertainties in experts' evaluation, econometric modeling or regression analysis would allow to extend the scope of the study and to generate additional findings and policy implications.

\section{Declarations}

Conflict of interest The authors declare that they have no competing interests. 
Availability of Data and Materials Not applicable.

Code Availability Not applicable.

Ethical Approval Not applicable.

Consent to Participate Not applicable.

Consent for Publication Not applicable.

\section{References}

Alexandri, E., \& Androutsopoulos, A. (2020). Multicriteria evaluation of ecolabels for the energy upgrade of dwellings in Greece. International Journal of Sustainable Energy, 39, 67-87. https:// doi.org/10.1080/14786451.2019.1644337

Arabatzis, G., \& Malesios, C. (2011). An econometric analysis of residential consumption of fuelwood in a mountainous prefecture of Northern Greece. Energy Policy, 39, 8088-8097

Arabatzis, G., \& Myronidis, D. (2011). Contribution of SHP Stations to the development of an area and their social acceptance. Renewable and Sustainable Energy Reviews, 15, 3909-3917

Ardavani, O., Zerefos, S., \& Doulos, L. T. (2020). Redesigning the exterior lighting as part of the urban landscape: The role of transgenic bioluminescent plants in Mediterranean urban and suburban lighting environments. Journal of Cleaner Production, 242, 118477. https://doi.org/10.1016/j. jclepro.2019.118477

ASSIST Project (2018). Report on National and European Measures Addressing Vulnerable Consumers and Energy Poverty, available at. http://www.assist2gether.eu/ eu-risultati.

Awaworyi Churchill, S., \& Smyth, R. (2020). Ethnic diversity, energy poverty and the mediating role of trust: Evidence from household panel data for Australia. Energy Economics, 86, 104663. https:// doi.org/10.1016/j.eneco.2020.104663

Balsara, S., Jain, P. K., \& Ramesh, A. (2021). An integrated methodology to overcome barriers to climate change mitigation strategies: a case of the cement industry in India. Environmental Science and Pollution Research. https://doi.org/10.1007/s11356-020-11566-6

Bakker, S., Zuidgeest, M., de Coninck, H., \& Huizenga, C. (2014). Transport, development and climate change mitigation: Towards an integrated approach. Transport Reviews, 34, 335-355. https://doi. org/10.1080/01441647.2014.903531

Balouktsis, I., Kekkeris, G. (2013). Energy education in Greece: Learning about renewable electrical energy perspectives. Proceedings of the 24th International Conference on European Association for Education in Electrical and Information Engineering, EAEEIE 2013, 6576515, 128-132 https://doi.org/10.1109/EAEEIE.2013.6576515.

Barrett, J., \& Scott, K. (2012). Link between climate change mitigation and resource efficiency: A UK case study. Global Environmental Change, 22, 299-307. https://doi.org/10.1016/j.gloenvcha.2011. 11.003

Birkenberg, A., Narjes, M. E., Weinmann, B., \& Birner, R. (2021). The potential of carbon neutral labeling to engage coffee consumers in climate change mitigation. Journal of Cleaner Production, 278, 123621. https://doi.org/10.1016/j.jclepro.2020.123621

Boemi, S. N., Avdimiotis, S., \& Papadopoulos, A. M. (2017). Domestic energy deprivation in Greece: A field study. Energy and Buildings, 144, 167-174. https://doi.org/10.1016/j.enbuild.2017.03.009

Boemi, S. N., \& Papadopoulos, A. M. (2019). Monitoring energy poverty in Northern Greece: the energy poverty phenomenon. International Journal of Sustainable Energy, 38, 74-88. https://doi.org/10. 1080/14786451.2017.1304939

Boemi, S. N., Samarentzi, M., \& Dimoudi, A. (2020). Research of energy behaviour and energy poverty of households in Northern Greece. IOP Conference Series: Earth and Environmental Science, 410, 012083. https://doi.org/10.1088/1755-1315/410/1/012083

Bonnail, E., Borrero-Santiago, A. R., Nordtug, T., Overjordet, I. B., Krause, D. F., \& Ardelan, M. V. (2021). Climate change mitigation effects: How do potential $\mathrm{CO} 2$ leaks from a sub-seabed storage site in the Norwegian Sea affect Astarte sp. bivalves? Chemosphere, 264, 128552. https://doi.org/10.1016/j. chemosphere.2020.128552 
Bos, K., \& Gupta, J. (2019). Stranded assets and stranded resources: Implications for climate change mitigation and global sustainable development. Energy Research and Social Science, 56, 101215. https:// doi.org/10.1016/j.erss.2019.05.025

Bowen, A., Campiglio, E., \& Tavoni, M. (2014). A macroeconomic perspective on climate change mitigation: Meeting the financing challenge. Climate Change Economics, 5, 1440005. https://doi.org/10. 1142/S2010007814400053

Butt, T. E., Giddings, R. D., \& Jones, K. G. (2012). Environmental sustainability and climate change mitigation-CCS technology, better having it than not having it at all! Environmental Progress and Sustainable Energy, 31, 642-649. https://doi.org/10.1002/ep.10590

Buzar, S. (2007). The "hidden" geographies of energy poverty in post-socialism: Between institutions and households. Geoforum, 38, 224-240. https://doi.org/10.1016/j.geoforum.2006.02.007

Chakravarty, S., \& Tavoni, M. (2013). Energy poverty alleviation and climate change mitigation: Is there a trade off? Energy Economics, 40, 67-73. https://doi.org/10.1016/j.eneco.2013.09.022

Charlier, D., \& Kahouli, S. (2019). From residential energy demand to fuel poverty: Income-induced Nonlinearities in the reactions of households to energy price fluctuations. Energy Journal, 40, 101-137. https://doi.org/10.5547/01956574.40.2.dcha

Cohen, B., Cowie, A., Babiker, M., Leip, A., \& Smith, P. (2021). Co-benefits and trade-offs of climate change mitigation actions and the Sustainable Development Goals. Sustainable Production and Consumption, 26, 805-813. https://doi.org/10.1016/j.spc.2020.12.034

Colenbrander, S., Gouldson, A., Sudmant, A. H., Papargyropoulou, E., Chau, L. W., \& Ho, C. S. (2016). Exploring the economic case for early investment in climate change mitigation in middle-income countries: a case study of Johor Bahru, Malaysia. Climate and Development, 8, 351-364. https://doi. org/10.1080/17565529.2015.1040367

Dagoumas, A., \& Kitsios, F. (2014). Assessing the impact of the economic crisis on energy poverty in Greece. Sustainable Cities and Society, 13, 267-278. https://doi.org/10.1016/j.scs.2014.02.004

De Martino Jannuzzi, G. (2010). Energy poverty and technology leap-frogging: A look at end-use efficiency programs for low income households in Brazil. Geopolitics of Energy, 32, 51-56

Doulos, L. T., Sioutis, I., Kontaxis, P. A., Zissis, G., \& Faidas, K. (2019). A decision support system for assessment of street lighting tenders based on energy performance indicators and environmental criteria: Overview, methodology and case study. Sustainable Cities and Society, 51, 101759. https://doi. org/10.1016/j.scs.2019.101759

Doulos, L. T., Sioutis, I., Tsangrassoulis, A., Canale, L., \& Faidas, K. (2020). Revision of threshold luminance levels in tunnels aiming to minimize energy consumption at no cost: Methodology and Case Studies. Energies, 13, 1707. https://doi.org/10.3390/en13071707

Drosos, D., Kyriakopoulos, G. L., Arabatzis, G., \& Tsotsolas, N. (2020). Evaluating customer satisfaction in energy markets using a multicriteria method: The case of electricity market in Greece. Sustainability, 12, 3862. https://doi.org/10.3390/su12093862

Edenhofer, O., Madruga, R. P., Sokona, Y., Seyboth, K., Matschoss, P., Kadner, S., Zwickel, T., Eickemeier, P., Hansen, G., Schlömer, S., \& von Stechow, C. (2011). Renewable energy sources and climate change mitigation: Special report of the intergovernmental panel on climate change. Renewable Energy Sources and Climate Change Mitigation Special Report of the Intergovernmental Panel on Climate Change. https://doi.org/10.1017/CBO9781139151153

Erickson, P. A., \& Lazarus, M. (2013). Implications of international GHG offsets on global climate change mitigation. Climate Policy, 13, 433-450. https://doi.org/10.1080/14693062.2013.777632

European Union Open Data Profile 2020. Energy statistical datasheets for the EU countries. Available online: https://data.europa.eu/euodp/en/data/dataset/information-on-energy-markets-in-eu-countrieswith-national-energy-profiles.

EU Energy Poverty Observatory. 2020a. Indicators \& Data. Available online: https://www.energypoverty. eu/indicators-data.

EU Energy Poverty Observatory 2020b. EPOV Indicators Dashboard. Methodology Guidebook. Available online: https://www.energypoverty.eu/sites/default/files/downloads/observatory-documents/20-07/ epov_methodology_guidebook.pdf.

European Commission 2015. Communication From the Commission to the European Parliament, The Council, The European Economic and Social Committee, The Committee of the Regions and the European Investment Bank a Framework Strategy for a Resilient Energy Union with a ForwardLooking Climate Change Policy. COM/2015/080 final. Available online: https://eur-lex.europa.eu/ resource.html?uri=cellar:1bd46c90-bdd4-11e4-bbe1-01aa75ed71a1.0001.03/DOC_1\&format=PDF (Accessed on March 10 2020). 
European Commission 2017. Monitoring progress towards the Energy Union objectives—key indicators. Second Report on the State of the Energy Union, Commission Staff Working Document. Brussels, 1.2.2017 SWD(2017) 32 final.

European Commission 2019a. National Renewable Energy Action Plans - EU Science Hub - European Commission. Available online: https:/ec.europa.eu/energy/en/topics/renewable-energy/nationalrenewable-energy-action-plans-2020.

European Commission 2019b. European Construction Sector Observatory. Policy fact sheet. Lithuania. Multi-apartment Renovation Programme. Thematic Objective 1. Available online: https://www.build up.eu/sites/default/files/content/ecso_pfs_lt_marp_2019.pdf

European Commission 2019c. Communication From the Commission to the European Parliament, The European Council, The Council, The European Economic and Social Committee and the Committee of the Regions. The European Green Deal. Brussels, 11.12.2019 COM (2019) 640 final. Available online https://eur-lex.europa.eu/legal-content/EN/TXT/?qid=1596443911913\&uri=CELEX:52019 DC0640\#document2 (accessed on March 10 2020).

Farrou, I., Androutsopoulos, A., Botzios-Valaskakis, A., Goumas, G., Andreosatos, C., Gavriil, L., \& Perakis, C. (2020). Energy efficiency in steam using industries in Greece. International Journal of Sustainable Energy, 39, 556-582. https://doi.org/10.1080/14786451.2020.1737066

Farrou, I., Kolokotroni, M., \& Santamouris, M. (2012). A method for energy classification of hotels: A casestudy of Greece. Energy and Buildings, 55, 553-562. https://doi.org/10.1016/j.enbuild.2012.08.010

Fekete, H., Kuramochi, T., Roelfsema, M., Elzen, M. D., Forsell, N., Höhne, N., Luna, L., Hans, F., Sterl, S., Olivier, J., van Soest, H., Frank, S., \& Gusti, M. (2021). A review of successful climate change mitigation policies in major emitting economies and the potential of global replication. Renewable and Sustainable Energy Reviews, 137, 110602. https://doi.org/10.1016/j.rser.2020.110602

Finland Future Research Centre. 2007. Development and Comparison of Sustainability Indicators (DECOIN) Project Presentation Leaflet. Available online: http://go.nature.com/2tnym6F.

Frangou, M., Aryblia, M., Tournaki, S., \& Tsoutsos, T. (2018). Renewable energy performance contracting in the tertiary sector Standardization to overcome barriers in Greece. Renewable Energy, 125, 829-839. https://doi.org/10.1016/j.renene.2018.03.001

Fuss, S., Szolgayová, J., Khabarov, N., \& Obersteiner, M. (2012). Renewables and climate change mitigation: Irreversible energy investment under uncertainty and portfolio effects. Energy Policy, 40, 59-68. https://doi.org/10.1016/j.enpol.2010.06.061

Gillard, R., Snell, C., \& Bevan, M. (2017). Advancing an energy justice perspective of fuel poverty: Household vulnerability and domestic retrofit policy in the United Kingdom. Energy Research and Social Science, 29, 53-61. https://doi.org/10.1016/j.erss.2017.05.012

Gouveia, J. P., Seixas, J., \& Long, G. (2018). Mining households' energy data to disclose fuel poverty: Lessons for Southern Europe. Journal of Cleaner Production, 178, 534-550. https://doi.org/10.1016/j. jclepro.2018.01.021

Grigoropoulos, C. J., Doulos, L. T., Zerefos, S. C., Tsangrassoulis, A., \& Bhusal, P. (2020). Estimating the benefits of increasing the recycling rate of lamps from the domestic sector: Methodology, opportunities and case study. Waste Management, 101, 188-199. https://doi.org/10.1016/j.wasman.2019.10.010

Hák, T., Janoušková, S., \& Moldan, B. (2016). Sustainable development goals: A need for relevant indicators. Ecological Indicators, 60, 565-573

Huang, F., Liu, J., Wang, Z., Shuai, C., \& Li, W. (2020). Of job, skills, and values: Exploring rural household energy use and solar photovoltaics in poverty alleviation areas in China. Energy Research and Social Science, 67, 101517. https://doi.org/10.1016/j.erss.2020.101517

IAEA (2005). Energy Indicators for Sustainable Development: Guidelines and Methodologies. International Atomic Energy Agency, United Nations Department of Economic and Social Affairs, International Energy Agency, Eurostat and European Environment Agency. Available online: https://www-pub. iaea.org/MTCD/Publications/PDF/Pub1222_web.pdf.

Jakučionytė-Skodienė, M., \& Liobikienė, G. (2021). Climate change concern, personal responsibility and actions related to climate change mitigation in EU countries: Cross-cultural analysis. Journal of Cleaner Production, 281, 125189. https://doi.org/10.1016/j.jclepro.2020.125189

Jewell, J., \& Cherp, A. (2020). On the political feasibility of climate change mitigation pathways: Is it too late to keep warming below $1.5^{\circ} \mathrm{C}$ ? Wiley Interdisciplinary Reviews: Climate Change, 11, 621. https://doi.org/10.1002/wcc.621

Jung, S. H., Lee, S. H., Min, J., Lee, M. H., \& Ahn, J. W. (2021). Analysis of the state of the art of international policies and projects on CCU for climate change mitigation with a focus on the cases in Korea. Sustainability, 13(1), 19. https://doi.org/10.3390/su13010019 
Kang, J. N., Wei, Y. M., Liu, L. C., Han, R., Yu, B. Y., \& Wang, J. W. (2020). Energy systems for climate change mitigation: A systematic review. Applied Energy, 263, 114602. https://doi.org/10. 1016/j.apenergy.2020.114602

Kapsalis, V. C., Kyriakopoulos, G. L., \& Aravossis, K. G. (2019). Investigation of ecosystem services and circular economy interactions under an inter-organizational framework. Energies, 12(9), 1734. https://doi.org/10.3390/en12091734

Karagiorgas, M., Tsoutsos, T., \& Moiá-Pol, A. (2007). A simulation of the energy consumption monitoring in Mediterranean hotels Application in Greece. Energy and Buildings, 39, 416-426. https:// doi.org/10.1016/j.enbuild.2006.07.008

Katsaprakakis, D. A., \& Christakis, D. G. (2016). The exploitation of electricity production projects from Renewable Energy Sources for the social and economic development of remote communities. the case of Greece: An example to avoid. Renewable and Sustainable Energy Reviews, 54, 341-349. https://doi.org/10.1016/j.rser.2015.10.029

Kolovos, K. G., Kyriakopoulos, G., \& Chalikias, M. S. (2011). Co-evaluation of basic woodfuel types used as alternative heating sources to existing energy network. Journal of Environmental Protection and Ecology, 12, 733-742

Kornek, U., Flachsland, Ch., Kardish, Ch., Levi, S., \& Edenhofer, O. (2020). What is important for achieving $2{ }^{\circ} \mathrm{C}$ ? UNFCCC and IPCC expert perceptions on obstacles and response options for climate change mitigation. Environmental Research Letters, 15, 024005

Kyprianou, I., Serghides, D. K., Varo, A., Gouveia, J. P., Kopeva, D., \& Murauskaite, L. (2019). Energy poverty policies and measures in 5 EU countries: A comparative study. Energy and Buildings, 196, 46-60

Kyriakopoulos, G. L., Kapsalis, V. C., Aravossis, K. G., Zamparas, M., \& Mitsikas, A. (2019). Evaluating circular economy under a multi-parametric approach: A technological review. Sustainability, 11(21), 6139. https://doi.org/10.3390/su11216139

Lakatos, E., \& Arsenopoulos, A. (2019). Investigating EU financial instruments to tackle energy poverty in households: A SWOT analysis. Energy Sources, Part B: Economics, Planning and Policy, 14, 235-253. https://doi.org/10.1080/15567249.2019.1667456

Larson, D.F., Dinar, A., Blankespoor, B. (2015). Aligning climate change mitigation and agricultural policies in eastern Europe and central Asia. World Scientific Reference on Asia and the World Economy, 6080, 69-151 https://doi.org/10.1142/9789814578622_0026. Available online: https:// openknowledge.worldbank.org/handle/10986/9338

Lazarou, S., Vita, V., Diamantaki, M., Karanikolou-Karra, D., Fragoyiannis, G., Makridis, S., \& Ekonomou, L. (2018). A simulated roadmap of hydrogen technology contribution to climate change mitigation based on Representative Concentration Pathways considerations. Energy Science and Engineering, 6, 116-125. https://doi.org/10.1002/ese3.194

Llera-Sastresa, E., Scarpellini, S., Rivera-Torres, P., Aranda, J., Zabalza-Bribián, I., \& Aranda-Usón, A. (2017). Energy vulnerability composite index in social housing, from a household energy poverty perspective. Sustainability, 9, 691. https://doi.org/10.3390/su9050691

Longe, O. M., \& Ouahada, K. (2018). Mitigating household energy poverty through energy expenditure affordability algorithm in a smart grid. Energies, 11, 947. https://doi.org/10.3390/en11040947

Lu, J., Ren, L., Zhang, C., Qiao, J., Kovacova, M., Streimikis, J. (2020a). Assessment of corporate social responsibility and its impacts on corporate reputation of companies in selected Balkan Countries former Yugoslavia States. Technological and Economic Development of Economy, 26(2), 504524; ISSN: 2029-4913/eISSN: 2029-4921; https://doi.org/10.3846/tede.2020.12069;

Lu, J., Ren, L., Zhang, C., Liang, M., Abrhám, J., Streimikis, J. (2020b). Assessment of Corporate Social Responsibility performance and state promotion policies: a case study of The Baltic States. Journal of Business Economics and Management, 21(4), 1203-1224; ISSN 1611-1699/eISSN 202944332020 https://doi.org/10.3846/jbem.2020.12738;

Manos, B., Bartocci, P., Partalidou, M., Fantozzi, F., \& Arampatzis, S. (2014). Review of public-private partnerships in agro-energy districts in Southern Europe: The cases of Greece and Italy. Renewable and Sustainable Energy Reviews, 39, 667-678. https://doi.org/10.1016/j.rser.2014.07.031

Manos, B., Partalidou, M., Fantozzi, F., Arampatzis, S., \& Papadopoulou, O. (2014). Agro-energy districts contributing to environmental and social sustainability in rural areas: Evaluation of a local public-private partnership scheme in Greece. Renewable and Sustainable Energy Reviews, 29, 85-95. https://doi.org/10.1016/j.rser.2013.08.080

Massetti, E., \& Tavoni, M. (2011). The cost of climate change mitigation policy in Eastern Europe and former Soviet Union. Climate Change Economics, 2, 341-370. https://doi.org/10.1142/S2010 007811000346 
Mavridou, T., \& Doulos, L. (2019). Evaluation of Different Roof Types Concerning Daylight in Industrial Buildings during the Initial Design Phase: Methodology and Case Study. Buildings, 9, 170. https:// doi.org/10.3390/buildings 9070170

Michaelowa, A., Hoch, S., Weber, A.-K., Kassaye, R., \& Hailu, T. (2021). Mobilising private climate finance for sustainable energy access and climate change mitigation in Sub-Saharan Africa. Climate Policy, 21(1), 47-62. https://doi.org/10.1080/14693062.2020.1796568

Middlemiss, L., \& Gillard, R. (2015). Fuel poverty from the bottom-up: Characterising household energy vulnerability through the lived experience of the fuel poor. Energy Research and Social Science, 6(120), 146-154. https://doi.org/10.1016/j.erss.2015.02.001

Milojevic-Dupont, N., \& Creutzig, F. (2021). Machine learning for geographically differentiated climate change mitigation in urban areas. Sustainable Cities and Society, 64, 102526. https://doi.org/10. 1016/j.scs.2020.102526

Nathan, H. S. K., \& Hari, L. (2020). Towards a new approach in measuring energy poverty: Household level analysis of urban India. Energy Policy, 140, 111397. https://doi.org/10.1016/j.enpol.2020.111397

Nerlich, B. (2012). "Low carbon" metals, markets and metaphors: The creation of economic expectations about climate change mitigation. Climatic Change, 110, 31-51. https://doi.org/10.1007/ s10584-011-0055-3

Neves, A. R., \& Leal, V. (2010). Energy sustainability indicators for local energy planning: Review of current practices and derivation of a new framework. Renewable and Sustainable Energy Reviews, 14, 2723-2735

Nikolaou, T., Skias, I., Kolokotsa, D., \& Stavrakakis, G. (2009). Virtual Building Dataset for energy and indoor thermal comfort benchmarking of office buildings in Greece. Energy and Buildings, 41, 14091416. https://doi.org/10.1016/j.enbuild.2009.08.011

Ntanos, S., Ntanos, A., Salmon, I., Ziatas, T. (2016). Public awareness on Renewable Energy Sources: a case study for the Piraeus University of Applied Sciences. Proceedings of the 5th International Symposium and 27th National Conference on Operational Research, EEEE 2016, 18-23.

Olson, K. (2010). An Examination of Questionnaire Evaluation by Expert Reviewers. Field Methods, 22(4), 295-318. https://doi.org/10.1177/1525822X10379795

Onat, N., \& Bayer, H. (2010). The sustainability indicators of power production systems. Renewable and Sustainable Energy Reviews, 14, 3108-3115

Papada, L., \& Kaliampakos, D. (2020). Being forced to skimp on energy needs: A new look at energy poverty in Greece. Energy Research and Social Science, 64, 101450. https://doi.org/10.1016/j.erss.2020. 101450

Papalambrou, A., \& Doulos, L. T. (2019). Identifying, Examining, and planning areas protected from light pollution. The case study of planning the first national dark sky park in Greece. Sustainability, 11, 5963. https://doi.org/10.3390/su11215963

Popp, A., Dietrich, J. P., Lotze-Campen, H., Klein, D., Bauer, N., Krause, M., Beringer, T., Gerten, D., \& Edenhofer, O. (2011). The economic potential of bioenergy for climate change mitigation with special attention given to implications for the land system. Environmental Research Letters, 6, 034017. https://doi.org/10.1088/1748-9326/6/3/034017

Pye, S., Dobbins, A., Baffert, C., Brajkovic, J., Deane, P., \& De Miglio, R. (2017). Energy poverty across the EU: analysis of policies and measures. Europe's Energy Transition. Insights Policy Making. https://doi.org/10.1016/B978-0-12-809806-6.00030-4

Qurat-ul-Ann, A. R., \& Mirza, F. M. (2020). Meta-analysis of empirical evidence on energy poverty: The case of developing economies. Energy Policy, 141, 111444. https://doi.org/10.1016/j.enpol.2020. 111444

Qurat-ul-Ann, A. R., \& Mirza, F. M. (2021). Determinants of multidimensional energy poverty in Pakistan: a household level analysis. Environment, Development and Sustainability. https://doi.org/10.1007/ s10668-020-01174-2

Qurat-ul-Ann, A. R., \& Mirza, F. M. (2021). Multidimensional Energy Poverty in Pakistan: Empirical Evidence from Household Level Micro Data. Social Indicators Research. https://doi.org/10.1007/ s11205-020-02601-7

Rodríguez, L. R., Ramos, J. S., Delgado, M. G., Molina, L. J., Félix, J. L. M., \& Domínguez, S. A. (2018). Mitigating energy poverty: Potential contributions of combining PV and building thermal mass storage in low-income households. Energy Conversion and Management, 173, 65-80. https://doi.org/10. 1016/j.enconman.2018.07.058

Röck, M., Saade, M. R. M., Balouktsi, M., Rasmussen, F. N., Birgisdottir, H., Frischknecht, R., Habert, G., Lützkendorf, T., \& Passer, A. (2020). Embodied GHG emissions of buildings-The hidden challenge for effective climate change mitigation. Applied Energy, 258, 114107. https://doi.org/10.1016/j.apene rgy.2019.114107 
Saavedra, G., Elgueta, S., Kehr, E., \& Jana, C. (2021). Climate change mitigation using breeding as a tool in the vegetables value chain. Studies in Systems, Decision and Control, 280, 67-77. https://doi.org/10. 1007/978-3-030-51047-3_5

Sadath, A. C., \& Acharya, R. H. (2017). Assessing the extent and intensity of energy poverty using Multidimensional Energy Poverty Index: Empirical evidence from households in India. Energy Policy, 102, 540-550. https://doi.org/10.1016/j.enpol.2016.12.056

Santamouris, M., Paravantis, J. A., Founda, D., Kolokotsa, D., Michalakakou, P., Papadopoulos, A. M., Kontoulis, N., Tzavali, A., Stigka, E. K., Ioannidis, Z., Mehilli, A., Matthiessen, A., \& Servou, E. (2013). Financial crisis and energy consumption: A household survey in Greece. Energy and Buildings, 65, 477-487. https://doi.org/10.1016/j.enbuild.2013.06.024

Sardianou, E. (2008). Barriers to industrial energy efficiency investments in Greece. Journal of Cleaner Production, 16, 1416-1423. https://doi.org/10.1016/j.jclepro.2007.08.002

Sharifi, A. (2021). Co-benefits and synergies between urban climate change mitigation and adaptation measures: A literature review. Science of the Total Environment, 750, 141642. https://doi.org/10.1016/j. scitotenv.2020.141642

Scarpellini, S., Rivera-Torres, P., Suárez-Perales, I., \& Aranda-Usón, A. (2015). Analysis of energy poverty intensity from the perspective of the regional administration: Empirical evidence from households in southern Europe. Energy Policy, 86, 729-738. https://doi.org/10.1016/j.enpol.2015.08.009

Schwanen, T., Banister, D., \& Anable, J. (2011). Scientific research about climate change mitigation in transport: A critical review. Transportation Research Part A: Policy and Practice, 45, 993-1006. https://doi.org/10.1016/j.tra.2011.09.005

Serrano-Medrano, M., García-Bustamante, C., Berrueta, V. M., Martínez-Bravo, R., Ruiz-García, V. M., Ghilardi, A., \& Masera, O. (2018). Promoting LPG, clean woodburning cookstoves or both? Climate change mitigation implications of integrated household energy transition scenarios in rural Mexico. Environmental Research Letters, 13, 115004. https://doi.org/10.1088/1748-9326/aad5b8

Sharma, S. V., Han, P., \& Sharma, V. K. (2019). Socio-economic determinants of energy poverty amongst Indian households: A case study of Mumbai. Energy Policy, 132, 1184-1190

Sihvonen, M., Pihlainen, S., Lai, T.-Y., Salo, T., \& Hyytiäinen, K. (2021). Crop production, water pollution, or climate change mitigation-Which drives socially optimal fertilization management most? Agricultural Systems, 186, 102985. https://doi.org/10.1016/j.agsy.2020.102985

Streimikiene, D., Lekavičius, V., Baležentis, T., Kyriakopoulos, G. L., \& Abrhám, J. (2020). Climate change mitigation policies targeting households and addressing energy poverty in European Union. Energies, 13, 3389. https://doi.org/10.3390/en13133389

Taylor, P. G., Abdalla, K., Quadrellie, R., \& Vera, I. (2017). Better energy indicators for sustainable development. Nature Energy, 2, 17117

Theodosiou, T. G., \& Ordoumpozanis, K. T. (2008). Energy, comfort and indoor air quality in nursery and elementary school buildings in the cold climatic zone of Greece. Energy and Buildings, 40, 22072214. https://doi.org/10.1016/j.enbuild.2008.06.011

Tsai, W. T. (2010). Energy sustainability from analysis of sustainable development indicators: A case study in Taiwan. Renewable and Sustainable Energy Reviews, 14, 2131-2138

Vlachokostas, C., Achillas, C., Michailidou, A. V., Tsegas, G., \& Moussiopoulos, N. (2020). Externalities of energy sources: The operation of a municipal solid waste-to-energy incineration facility in the greater Thessaloniki area, Greece. Waste Management, 113, 351-358. https://doi.org/10.1016/j.wasman. 2020.06.015

Walsh, C. L., Dawson, R. J., Hall, J. W., Barr, S. L., Batty, M., Bristow, A. L., Carney, S., Dagoumas, A. S., Ford, A. C., Harpham, C., Tight, M. R., Watters, H., \& Zanni, A. M. (2011). Assessment of climate change mitigation and adaptation in cities. Proceedings of the Institution of Civil Engineers: Urban Design and Planning, 164, 75-84. https://doi.org/10.1680/udap.2011.164.2.75

Yadav, P., Malakar, Y., \& Davies, P. J. (2019). Multi-scalar energy transitions in rural households: Distributed photovoltaics as a circuit breaker to the energy poverty cycle in India. Energy Research and Social Science, 48, 1-12. https://doi.org/10.1016/j.erss.2018.09.013

Yuksel, I. (2008). Energy utilization, renewables and climate change mitigation in Turkey. Energy Exploration and Exploitation, 26, 35-52. https://doi.org/10.1260/014459808784305798

Zamparas, M., Kapsalis, V. C., Kyriakopoulos, G. L., Aravossis, K. G., Kanteraki, A. E., Vantarakis, A., \& Kalavrouziotis, I. K. (2019). Medical waste management and environmental assessment in the Rio University Hospital Western Greece. Sustainable Chemistry and Pharmacy, 13, 100163. https://doi. org/10.1016/j.scp.2019.100163

Zamparas, M., Kyriakopoulos, G. L., Kapsalis, V. C., Drosos, M., \& Kalavrouziotis, I. K. (2019). Application of novel composite materials as sediment capping agents: Column experiments and modelling. Desalination and Water Treatment, 170, 111-118. https://doi.org/10.5004/dwt.2019.24909 
Zerriffi, H., \& Wilson, E., (2010). Leapfrogging over development? Promoting rural renewables for climate change mitigation. Energy Policy, 38(4), 1689-1700.

Zhang, C. H., Wang, Q., Zeng, S. Z., Baležentis, T., Štreimikienè, D., Ališauskaitė-Šeškienė, I., \& Chen, X. L. (2019). Probabilistic multi-criteria assessment of renewable micro-generation technologies in households. Journal of Cleaner Production, 212, 582-592. https://doi.org/10.1016/j.jclepro.2018.12. 051

Zhang, R., \& Fujimori, S. (2020). The role of transport electrification in global climate change mitigation scenarios. Environmental Research Letters, 15, 034019. https://doi.org/10.1088/1748-9326/ab6658

Publisher's Note Springer Nature remains neutral with regard to jurisdictional claims in published maps and institutional affiliations. 